\title{
Los programas de ajuste del FMI: con- tenido, bases teórico-analíticas y resultados
}

\author{
Lisandro E. Abrego
}

\begin{abstract}
Desde su creación en 1947, el Fondo Monetario Internacional ha desempeñado un papel importante en los países subdesarrollados con problemas de inflación y balanza de pagos. Asimismo, su enfoque de estabilización, desarrollado formalmente en los años cincuenta, ha sido bastante influyente tanto a nivel de algunos circulos académicos como a nivel de funcionarios gubernamentales y de otros organismos internacionales de financiamiento. En realidad, puede decirse que muchos de los enfoques de estabilización que han sido propuestos y ensayados en las últimas décadas no constituyen sino variantes del enfoque del FMI.
\end{abstract}

Siendo el enfoque del FMI tan importante y esta institución tan influyente en las decisiones de política económica de una gran diversidad de paises subdesarrollados, es útil estudiar, preferiblemente con un espiritu crítico, el contenido y los fundamentos del ajuste propuesto por el Fondo, asi como lo que en general suelen ser sus resultados, con el objeto de identificar tanto sus bondades como sus deficiencias. Este es precisamente el propósito de este trabajo, aunque su espíritu crítico ha contribuido a sesgarlo hacia las deficiencias del enfoque del FMI.

El trabajo se ha estructurado en cuatro partes. En la primera se presenta la concepción del Fondo sobre los desequilibrios macroeconómicos y sus fundamentos teórico-analíticos, así como el contenido de sus programas de ajuste. En la segunda se ofrecen algunos planteamientos en torno a los efectos colaterales de estos programas, en especial sobre su impacto en el nivel de actividad económica, el empleo y la 
distribución del ingreso. En la tercera parte se evalúan la eficacia de los programas del Fondo en los paises subdesarrollados en general durante las últimas tres décadas; se trata también, de manera separada, la experiencia de estabilización en El Salvador durante el decenio pasado. Asimismo, se ofrecen algunas hipótesis explicativas en torno a los resultados de los programas del Fondo. Por último, en la cuarta parte, se ofrecen algunas apreciaciones sobre la necesidad de fomular un enfoque de estabilización alternativo y sobre las limitaciones de los que han sido propuestos en los últimos años. Asimismo, se senalan algunas condiciones que minimizarian los costos del ajuste, asi como algunas modalidades que podrian contribuir a hacer frente a tal problema.

\section{Contenido y bases teorico-analiticas de los programas de ajuste del FMI}

Los programas de ajuste del FMI son programas de estabilización económica. Estos, en términos generales, buscan ajustar la demanda interna de una economia a la oferta. El horizonte temporal de estos programas suele ser bastante corto (1-2 años); es decir la corrección de dicho desajuste es un resultado que ha de producirse con bastante rapidez. De ahi que el ajuste que se pretende lograr se centre fundamentalmente en la necesidad de contraer la demanda, algo más rápido y más fácil de lograr, al menos en teoria, que la reactivación de la oferta.

En la mayoría de los casos, el desajuste entre damanda y oferta se refleja en dos desequilibrios macroeconómicos básicos, uno de carácter interno y otro de naturaleza "externa". El desequilibrio interno consiste en una inflación elevada, particularmente con relación a la inflación mundial.' El desequilibrio externo, por su parte, consiste en un déficit más o menos persistente en la balanza de pagos, particularmente en la cuenta corriente. Este déficit, sin embargo, no es un problema por el simple hecho de constituir una ausencia de equilibrio; más bien, se vuelve un problema cuando se torna incompatible con las entradas de capital normales o sostenibles en el largo plazo, ${ }^{2}$ o cuando se traduce en un fuerte drenaje de las reservas internacionales.

Los programas de estabilización del Fondo tienen asi un objetivo de

1. Obsénese que se ignora completamente el otro desequilibrio macroeconómico interno señalado por la teoria macroeconómica convencional: el desempleo.

2. Sobre la sustentabilidad de un déficit en cuenta corriente véase J. Salop y E. Spitäller (1980). Buira (1983) presenta una discusión crítica sobre la definición de sustentabilidad de la posición externa de un país. 
inflación y otro de balanza de pagos. La expresión cuantitativa de estos objetivos constituye lo que se denomina "metas finales" de los programas de ajuste del Fondo. Aunque estos dos desequilibrios suelen presentarse simultáneamente, generalmente es la presencia del desequilibrio externo y en particular la pérdida incontrolable de reservas intemacionales, y\% de acceso a los mercados financieros mundiales, lo que suele llevar a los paises a embarcarse en un programa de estabilización.

¿Cuáles son los instrumentos de que hacen uso estos programas a fin de alcanzar sus objetivos? Para responder adecuadamente a esta pregunta es necesario pasar revista a la concepción del FMI (compartida por su institución gemela, el Banco Mundial) sobre el origen de los desequilibrios macroeconómicos. En la concepción del Fondo, el origen de tales desequilibrios está vinculado generalmente a los siguientes factores:

- Shocks externos que se traducen generalmente en un fuerte deterioro en los términos de intercambio (shocks de oferta)

- Una politica macroeconómica sobreexpansiva (crecimiento excesivo de la demanda)

- Asociado al factor anterior, una distorsión en la estructura de precios relativos de la economia en detrimento de los bienes transables y la consiguiente sobrevalución del tipo de cambio ${ }^{3}$

Actualmente, sin embargo, cualquiera que sea el origen del desequilibrio, la receta general suele ser siempre la misma: la demanda interna debe ser ajustada a la oferta. Originalmente (en los años cincuenta), el Fondo dividia los desequilibrios externos en dos tipos: desequilibrios fundamentales y desequilibrios temporales (o reversibles). Los primeros, de naturaleza permanente, tendrian su origen en factores reales (por ejemplo, caida irreversible en los términos de interncambio, ensanchamiento de la brecha de productividad, etc.); mientras que los segundos estarian asociados a un manejo inadecuado de la política económica interna (Meller 1987; Buira 1983). Estos desequlibrios requeririan un tratamiento de política económica distinto: en el caso de los desequilibrios fundamentales, la solución consistiria en ajustar el tipo de cambio; en el caso

3. De hecho, la sobrevaluación del tipo de cambio puede resultar también de un shock de oferta, como un deterioro irreversible de los términos de Intercambio (por ejemplo), pues en este caso el tipo de cambio de equilibrio habrá cambiado. 
de los desequilibrios temporales, se deberia hacer uso de los recursos del Fondo y se modificaria la politica económica interna, sin ajustar el tipo de cambio (Meller 1990; Buira 1983). ${ }^{4}$ Con el tiempo, este enfoque habria de cambiar notablemente, no sin dejar una marca - hasta ahora permanente- en la implementación práctica de los programas del Fondo, como veremos más adelante.

Aunque en las últimas dos décadas los shocks externos han jugado un papel de gran importancia en los desequilibrios macroeconómicos en los paises subdesarrollados - particularmente en los no exportadores de petróleo-, la atención ha tendido a centrarse en los factores internos relacionados con la política macroeconómica. A este respecto, las políticas macroeconómicas expansivas estarian vinculadas principalmente a un déficit fiscal elevado, que sería el resultado de una voluminosa inversión pública, de la existencia de empresas públicas deficitarias, de una política de subsidios (y precios) demasiado generosa por parte del Estado y del servicio de la deuda pública, tanto interna como externa (Banco Mundial 1988)

Este déficit fiscal, al ser financiado en los países subdesarrollados en buena medida mediante la emisión de dinero - en virtud de su carencia de un mercado de capitales desarrollado-, constituiria el factor responsable de la inflación. Esto porque tal emisión se traduciria en un nivel de demanda superior al de la oferta interna de bienes y servicios. De ahi que la eliminación, o drástica reducción, del déficit fiscal, constituya generalmente un elemento fundamental dentro del contenido de los programas antiinflacionarios del Fondo. En efecto, éste constituye uno de los de los principales "criterios de ejecución" de los programas fondomonetaristas.

En un marco de régimen de tipo de cambio fijo, la práctica de una política macroeconómica expansiva y la consiguiente sobreemisión monetaria seria también la causa del desequilibrio externo. Esto en la medida en que conduciria a la generación de un sesgo en la estructura de

4. Con un desequilibrio temporal coincidiendo con una sobrevaluación cambiara, desde el punto de vista del restablecimiento del tipo real de equilibrio, tal enfoque sería conceptualmente correcto sólo si los precios son flexibles a la baja. Si tal flexibilidad no existe, el tipo de cambio real seguiria desalineado y la sola modificación de la política económica interna, aunque podría restablecer el equilibrio externo, no restablecería el tipo de cambio real de equilibrio e incrementaria el desempleo. En este caso de inflexibilidad, por lo tanto, se requeriria simultáneamente una modificación del tipo de cambio nominal para que, teóricamente, a la vez que se restablezca el equilibrio externo y el tipo de cambio de equilibrio, el desempleo no caiga (Edwards 1988). 
precios relativos, y de la producción, en contra de los bienes transables. ${ }^{5}$ La idea es que la oferta de bienes no transables es bastante rigida en el corto plazo, en contraposición a la de bienes transables, que, mieritras exista capacidad de importación, sería prácticamente ilimitada para un pais pequefio en el mercado mundial. De ahi que el execeso de demanda que la política macroeconómica sobreexpansiva crearía en el merca- . do doméstico, se resolvería en el mercado de bienes no transables principalmente via precios, y en el mercado de no transables via cantidades, y que el precio relativo de los primeros se incremente; es decir, que el tipo de cambio se sobrevalúe.

Analíticamente, pueden distinguirse dos efectos de la macropolíticas sobreexpansivas. Por una parte, se tendria un alza en el nivel general de precios debido a la forma en que el desequlibrio se resuelve en el mercado de no transables. Por otra, en el contexto de un régimen de tipo de cambio fijo, la evolución dispareja de los precios en los sectores citados se tornaria en favor de los bienes no transables. El resultado seria la sobrevaluación del tipo de cambio, la disminucación de la competitividad de los bienes transables y el deterioro de la balanza comercial y el sector externo en general (Ahamed 1986).

Ahora bien, puesto que el el problema principal con el déficit fiscal es la sobrecreación de dinero, su abatimiento debe manifestarse necesariamente en una menor expansión (o en una contracción) de los agregados monetarios. En una economia pequeha, abierta y con un tipo de cambio fijo, esto se lograria ejerciendo un mayor control sobre la tasa de crecimiento del crédito doméstico, sobre todo del crédito al sector público. EI control del crédito, especialmente del crédito público, constituye asi el segundo gran instrumento de los programas de estabilización fondomonetaristas, y su "criterio de ejecución" principal. La restricción del crédito, sin embargo, se aplica tanto al sector público como al sector privado. ${ }^{6}$ En el sector público, el control crediticio puede manifestarse ya sea en la contracción del gasto o en la elevación de los ingresos. ${ }^{7}$ En el sec-

5. Como veremos más adelante, la versión monetarista sobre el desequilibrio externo no plantea el problema en términos de desajustes de precios relativos, sino en términos de exceso de acervo de dinero con relación asu demanda.

6. De acuerdo con Johnson y Salop (1980, pp. 8-9), "el sector privado también contribuye al problema cuando los términos y disponibilidad de crédito estimulan la mantención de niveles de consumo insostenibles y la inversión en proyectos que no se implementarian si las tasas de interés reflejaran correctamente el verdadero costo de oportunidad de pedir prestado en los mercados mundiales".

7. En el caso del ajuste de las finanzas del gobierno central, Crockett (1981, p. 
tor privado, el mayor control sobre el crédito se manifiesta tanto en una contracción del consumo como de la inversión.

La modificación de la política macroeconómica (fisal y monetariocrediticia) sería sólo una parte del paquete de medidas de los programas del Fondo. De acuerdo con el diagnóstico esbozado arriba sobre las causas internas de los desequilibrios, éso seria insuficiente, tanto de cara a la correción del desequilibrio externo como por la magnitud de los efectos recesivos que generaria. En un mundo de precios inflexibles a la baja, ello tampoco bastaria para restablecer el tipo de cambio de equilibrio. De ahi que se postule también la necesidad de la política cambiaria, es decir, de la devaluación, para corregir los desequilibrios macroeconómicos. La idea consiste en que la devaluación, en tanto capaz de incidir sobre los precios relativos, magnificaria el impacto positivo de la política macroeconómica restrictiva sobre el sector externo. Al mismo

67) ha señalado que "el rol central de la política fiscal como instrumento de estabilización conduce al problema de si los medios específicos por los cuales un impacto fiscal global es alcanzado son relevantes para el éxito del programa". El problema se deriva principalmente del hecho de que "medidas que afectan la tributación y el gasto público tienen implicaciones potenciales sobre la distribución del ingreso, que a su vez tiene que ver con la aceptabilidad social y política del paquete de estabilización". Aunque Crockett no lo dice explicitamente - aduciendo que el enjuiciamiento "debe ser dejado a las autoridades directamente involucradas" -, no parecen existir razones convincentes para sostener que la reducción del déficit fiscal mediante la contracción del gasto, sea superior en términos de estabilización al aumento de los ingresos. Algunos economistas sostienen, inclusive que la elevación de los impuestos pudiera ser una mejor alternativa, entre otras razones porque "el aumento en ingresos tributarios suele afectar todas las actividades en forma más pareja que un recorte del gasto, facilitando asi un ajuste en precios y no en producción" (Ramos, 1986, p. 46). Esta visión contrasta con la actuación del Fondo: en sus programas de estabilización, cuando se trata de ajustar las cuentas del gobierno central, parece existir una preferencia marcada por la disminución del gasto. En esta línea, los ajustes en los precios de los servicios prestados por las empresas públicas, no suelen constituir sino una forma de reducir el gasto mediante el recorte de subsidios. Esto no significa que reducciones en el gasto no suelan ir acompañadas de incrementos en los ingresos tributarios (los datos presentados en Edwards (1990) reflejan precisamente eso); el punto está en que el ajuste de las finanzas suele recaer más sobre el primero que sobre los segundos. Los programas de estabilización respaldados por el FMI parecen conllevar, en este sentido, un marcado sesgo ideológico en contra de la intervención del Estado en la economía, a costas de provocar efectos regresivos en la distribución del ingreso y, posiblemente, de un menor nivel de actividad económica. 
tiempo, amortiguaria la contracción de la actividad económica en la medida en que conducirá a la expansión de las industrias de bienes transables, como resultado del aumento de su precio relativo y consiguientemente de su competitividad (Corden, 1986). ${ }^{8}$ Asi, el tipo de cambio (la devaluación) constituiria el otro gran instrumento para la estabilización económica en los programas ajuste del Fondo.

7 -Dependiendo de las circunstancias concretas de cada pais, en la práctica las políticas fiscal, monetario-crediticia y cambiara, que constituyen la parte fundamental de los programas del Fondo, ${ }^{9}$ suelen ser acompañadas por otras políticas. Entre las más importantes dentro de éstas se encuentran el incremento de las tasas de interés, reforma tributaria, liberalización comercial y liberalización de los régimenes cambiarios, reformas a las fijación de precios por las empresas públicas, racionalización de precios y ajustes de precios al productor (Edwards 1990, p. 636). ${ }^{10}$ Algunas de estas medidas complementarias siguen respondiendo a la necesidad de contraer la demanda interna o a la de reducir el déficit fiscal; otras, sin embargo, aunque pueden tener un impacto sobre la demanda en el corto plazo, buscan también incidir sobre la oferta y la eficiencia global de la economia (tal es el caso, por ejemplo, de de los aumentos de las tasas de interés, de la liberalización comercial y de las reformas tributarias de largo alcance, sobre todo las fundadas en la supply side economics)

En cuanto al trasfondo teórico de los programas del Fondo, una buena parte se encuentra en la teoria macroeconómica convencional, particularmente en su versión monetarista. Este es el caso sobre todo para la concepción del desequilibrio interno (inflación), en la medida que se le explica fundamentalmente como resultado de un crecimiento monetario excesivo. La idea se basa en la ecuación de cambio que se deriva de la

8. Como veremos más adelante, esta perspectiva contrasta con la perspectiva "estructuralista" que ve en la devaluación una politica contractiva.

9. Según datos presentados en Edwards (1990, p. 636), de los programas de alta condicionalidad del Fondo implementados en varios paises subdesarrollados entre 1983 y 1985, alrededor del 70\% contenian medidas de política fiscal, el $100 \%$ contenían control del crédito al sector público, el $97 \%$ control del crédito y los agregados monetarios en general y el $79 \%$ devaluación. Los programas que no incluyeron devaluación correspóndieron a paises que debido a restricciones institucionales, como su pertenencia a una unión monetaria y/o su carencia de moneda nacional, no podian alterar el tipo de cambio.

10. Es en estas otras políticas donde reside el modesto elemento de flexibilidad de los programas del Fondo. 
teoria cuantitativa del dinero, según la cual, dado un volumen de transacciones o de producción (de pleno empleo), el valor de éstas variará en forma directamente proporcional a la oferta monetaria. Esta es la versión monetarista de la inflación de la macroeconomia convencional para una economia cerrada. Se resume en la famosa ecuación: $M V=P Q$, donde $M$ es la oferta monetaria, $V$ la velocidad de circulación del dinero (que se asume constante), $P$ el nivel general de precios y $Q$ la producción física (de pleno empleo).

La versión correspondiente para una economia abierta sostiene que el nivel de precios está determinado por la inflación mundial y el tipo de cambio. En su modalidad de monetarismo global, esta versión supone una intergración completa de los mercados nacionales al mercado mundial, por lo que los precios internos vendrian dados por la ecuación $\mathrm{P}=$ $\mathrm{eP}^{*}$, donde e es el tipo de cambio nominal y $\mathrm{P}^{*}$ es el precio internacional expresado en moneda extranjera (Meller 1990, p. 60). Ahora bien, si, como hace este enfoque, se parte de un régimen de tipo de cambio fijo. la inflación, entendida como un aumento continúo en el nivel general de precios, no tendria por qué estar vinculada al tipo de cambio. En cuanto a la inflación mundial, para un pais pequeño en el mercado internacional -que es con el que trabaja el monetarismo de economia abierta-, ésta es una variable totalmente exógena al manejo de su política económica. El foco de atención del Fondo no es ese tipo de factores exógenos, sino los vinculados al manejo de la política económica doméstica.

De este modo, en la práctica el FMI se queda con la versión de la hipótesis de la ecuación de cambio," pese a ser un planteamiento formulado originalmente para una economia cerrada que se encuentra en pleno empleo, características que tienen muy poco que ver con la mayoria de economias subdesarrolladas. La condición de pleno empleo, sin embargo, sería sólo un caso especial de una teoría más general; es decir, una economia no necesitaria estar operando a plena capacidad para que un crecimiento monetario "excesivo" resulte en una elevación del nivel de precios: basta con que, para un nivel dado de oferta independientemente de que esta sea o no de pleno empleo-, haya una

11. Las dos versiones monetarista citadas no son necesariamente coherentes, pues si se parte de una economia completamente integrada al mercado mundial los precios internos están determinanados completamente por los precios mundiales, independientemente de lo que esté sucediendo con el acervo nacional de dinero. Esto es el resultado también del supuesto de comerciabilidad internacional para todos los bienes. En el caso de integración completa, lo que esté pasando con el acervo de dinero sería relevante sólo de cara al desequilibrio externo, como veremos más adelante. 
demanda nominal excesiva (Ahamed 1986). En general, seria tal exceso de demanda lo que conducirá a un incremento de precios; y mientras ese exceso de demanda se mantenga, habrá inflación, es decir un incremento contínuo en el nivel general de precios.

En cuanto a la condición de economía cerrada, es importante la división de la economia entre bienes transables y no transables que presentamos arriba, la cual está ausente en la versión monetarista de la economía abierta - con su supuesto de que todos los bienes son transables- pero que el Fondo asume en la práctica. Con tal división, podría decirse que un sistema económico abiento contendria un subsistema cerrado desde el punto de vista de la generación de oferta. Este subsitema sería el sector de bienes no transables, cuya dinámica de precios, dado un nivel de oferta, estaria asi determinada por lo que suceda con el crecimiento monetario doméstico.

En lo que al desequilibrio externo se refiere, la base teórica de estos programas se encuentra en la macroeconomia de la economia abierta -que surge en los paises desarrollados en los anos cincuenta y sesenta-, en particular en los enfoques teóricos sobre la balanza de pagos. Aunque en los últimos años el monetarismo ha aumentado su influencia sobre el pensamiento económico del FMI, el fundamento teórico del enfoque del Fondo sobre el desequilibrio externo se encuentra no sólo en el enfoque monetario de la balanza de pagos (EMBP), sino también en un híbrido de los enfoques de elasticidades y absorción, y del modelo de la economia dependiente. Si bien el EMBP ha llegado a ser el dominante en el FMI, tanto por razones analíticas como por razones prácticas (de implementación de sus programas), las medidas encaminadas a corregir el desequilibrio externo contenidas en los programas de estabilizacion respaldados por el FMI integran elementos de los distintos enfoques, desarrollados todos (incluyendo el EMBP en sus puntos esenciales, como veremos abajo) antes de los sesenta. ${ }^{12}$ Sin pretender en modo alguno realizar una exposición completa de ellos, a continuación reseñaremos brevemente sus elementos fundamentales de cara al programa del Fondo. ${ }^{13}$ Dada la mayor influencia del EMBP en el modelo del FMI, nos detendremos un poco más en él.

12. El modelo de flujos (o Mundell-Flemming) y el modelo de activos, desarrollados durante y después de los sesenta, respectivamente, parecen haber ejercido una menor influencia en el Fondo.

13. Exposiciones más amplias y completas se encuentran, por ejemplo, en Arellano (1986), Frenkel (1980), Kenen (1985), Meller (1987) y McKinnon (1981). 
Aunque en los programas de estabilización raramente hay una referencia explicita a la condición Marshall-Lerner ${ }^{14}$ por la que el enfoque de las elasticidades es más conocido, ésta se encuentra implícitamente en la creencia del Fondo en torno a que una devaluación mejora la balanza comercial. La preocupación por los precios relativos de los sectores transables y no transables y esta peculiar división sectorial de la economia refleja la influencia del modelo de la economia dependiente en el enfoque el FMI. Este modelo, y el enfoque de la absorción, ha contribuido a la división de las políticas de estabilización en políticas de reducción y de reorientación del gasto interno que contiene la visión del Fondo. Esto puede verse a través del enfoque de la aborción. Este toma como punto de partida la identidad de las cuentas nacionales

$$
X-M=Y-A \text {, }
$$

donde:

$$
\begin{aligned}
& X=\text { exportaciones } \\
& M=\text { importaciones } \\
& Y=\text { Ingreso interno } \\
& A=\text { gasto interno o absorción (consumo + inversión) }
\end{aligned}
$$

El enfoque postula que un desequilibrio en la cuenta corriente de la balanza de pagos no es sino el reflejo de un desequilibrio entre el nivel de gasto e ingreso internos; es decir, del hecho de que un pais está viviendo por encima de sus medios. De ahi que para la reducción del desequilibrio haya que contraer el gasto, A. Esto se buscaria lograr con una política macroeconómica restrictiva, como las políticas de contracción de la demanda descritas arriba. Hasta aqui llegaria el modelo agregado del enfoque de la absorción. Para plantear el problema en términos de modificación de la composición del gasto (y de la producción) hay que recurrir al modelo, más desagregado, de la economia dependiente, y es aqui donde aparecen la devaluación y los precios relativos. ${ }^{15}$

14. Esta condición afirma que para que una devaluación mejore la balanza comercial la suma de los valores absolutos de las elasticidades precio de las exportaciones e importaciones debe ser mayor que uno.

15. En efecto, puesto que la demanda de bienes no transables es por definición igual a su oferta doméstica, el desequilibrio entre $A$ y $Y$ en la identidad del enfoque de la absorción ocurre en el sector de bienes transables, cuya demanda doméstica es superior a la oferta doméstica. De ahi que haya que reorientar la producción hacia los bienes transables y/o reducir su demanda. Esto sería logrado por la devaluación que, al aumentar el precio relativo de los transables, estimularia su producción interna y desestimularia su consumo. 
En el enfoque de la absorción no hay una explicación sobre el origen del desequilibrio entre ingreso y gasto interno; además, al igual los enfoques con que forma el híbrido de que hablamos arriba, sólo se preocupa por la cuenta corriente. El enfoque monetario, por su parte; busca una explicación al mismo y al desequilibrio en la balanza de pagos global. Dicha explicación la encuentra exclusivamente en la esfera monetaria de la economia, en tanto que concibe el desequilibrio externo como un fenómeno puramente monetario. Partiendo de la identidad de las cuentas del sector monetario

$$
M=R+C,
$$

donde:

$$
\begin{aligned}
& M=\text { oferta monetaria } \\
& R=\text { Reservas internacionales } \\
& C=\text { Crédito doméstico, }
\end{aligned}
$$

y del postulado de que la demanda de dinero es una función estable del nivel de ingreso, en'su versión más simple, el enfoque monetario afirma que, en una economia abierta y con tipo de cambio tijo, ${ }^{16}$ el desequilibrio en la balanza de pagos se produce por una expansión del crédito superior al aumento deseado de saldos monetarios en manos del público. De ahi que éste trate de deshacerse del exceso de dinero en sus manos importando bienes y servicios o exportando titulos valores. En cualquiera de los casos, el nivel de reservas internacionales disminuye; es decir, la balanza de pagos se deteriora. De acuerdo al enfoque monetario, por lo tanto, para corregir el desequilibrio en la balanza de pagos, debe ejercerse un estricto control sobre la tasa de expansión del crédito interno, de manera que el crecimiento de la oferta monetaria no supere al crecimiento de la demanda de dinero. Este punto constituye un aspecto fundamental en el marco analítico de programación usado por el FMI en la práctica.

En esta visión monetarista, los precios relativos no tendrian ningún rol en el ajuste externo. Si la devaluación habria de tener un rol en tal ajuste, éste no consistiria en la alteración de la estructura de precios de la economia, sino más bien en la alteración de su nivel. (Esto resulta del supuesto de comerciabilidad internacional para todos los bienes en el

16. El elemento tipo de cambio fijo es crucial acá, pues de lo contarario la autoridad monenetaria puede controlar la oferta de dinero y no sólo el componente interno de ésta (crédito interno, básicamente). 
EMBP). De esta manera, en este enfoque la devaluación es importante sólo en la medida en que genera un mayor nivel interno de precios y de esa manera contrae el acervo real de dinero, contribuyendo a la restauración del equilibrio en el mercado monetario. Dada la importancia que en la implementación práctica de los programas del FMI se le asgina al tipo de cambio real -esta variable constituye una de las "metas intermedias" de esos programas-, pareciera que en este punto el Fondo se distancia un tanto de la visión monetarista. Una variable que si tendria un rol importante en el EMBP, y que está completamente ausente en los enfoques anteriores -pues éstos centran su preocupación exclusivamente en la cuenta corriente- es la tasa de interés en tanto que se seria capaz de incidir sobre los movimientos internacionales de capital (Meller 1987) $^{17}$

EI EMBP toma prestado mucho del modelo desarrollado a finales de los ahos cincuenta en el mismo FMI por J.J. Polak, ${ }^{18}$ quien fuera por mucho tiempo el director del Departamento de Investigaciones de ese organismo. De hecho, el marco contable que sirve de base al EMBP corresponde fundamentalmente al modelo desarrollado por Polak. El modelo de Polak resume lo que ahora se conoce como programación financiera, que constituye el marco analítico básico para la elaboración de los programas de ajuste del FMI. Tal como la ha definido Edwards (1990, p. 613), "la programación financiera (PF) consiste en un conjunto de ecuaciones simples que relacionan, para el caso de una economía pequeña y abierta con un tipo de cambio fijo, el comportamiento del sector monetario con la balanza de pagos" (cursivas nuestras). El enfoque de PF contiene asi el tipo de economia que contituye el foco de atención y análisis del EMBF, y su relación básica.

No estaria de más recordar que el enfoque de la PF respondia originalmente a la necesidad de hacer frente a los desequilibrios temporales; es decir, a los desequilibrios cuya corrección no requería una devaluación. De ahi que la devaluación -que en el enfoque original del FMI habria de usarse sólo para corregir desequilibrios fundamentales- esté formalmente excluida del modelo de PF.

Siguiendo a Edwards (1990, p. 615), puede decirse que el modelo de Polak se basa en tres elementos fundamentales: i) el supuesto de que la demanda de dinero es una función estable del nivel de ingreso; ii) el supuesto de que los flujos de capital y las exportaciones son exógenos,

17. Esta es una relación que el EMBP toma del modelo Mundell-Fleming.

18. Véase J.J. Polak (1957). Una exposición temprana sobre los aspectos conceptuales del EMBP es Johnson (1961). 
y que las importaciones guardan una relación proporcional con el nivel de ingreso, que es también una variable exógena; iii) la identidad de las cuentas del sector monetario que divide los cambios en la oferta monetaria doméstica en dos componentes: cambios en el crédito interno y cambios en las reservas internacionales. Estos tres elementos sugieren que estamos, efectivamente, ante la versión más difundida del EMBP.

Sobre la base de estos elementos, el modelo de Polak arrivaba a tres conclusiones básicas (Edwards 1990, pp. 615-16): i) en una economia pequena, abierta y con tipo de cambio fijo, las cantidades de dinero reales y nominales son endógenas; ii) el principal instrumento de control. monetario es el crédito interno; iii) en el corto plazo, y para un nivel dado de ingreso, las variaciones del crédito interno son iguales a las variaciones de las reservas internacionales. Estas son precisamente las conclusiones básicas del EMBP.

Aunque, como han sefialado algunos economistas (Edwards 1990; Buira 1983), dado el carácter cuasi-secreto de los programas del Fondo, se conoce poco de los detalles operativos de la PF utilizada por esa institución, ${ }^{19}$ parece que ésta habria cambiado muy poco desde que nació hace tres décadas, y, pese a los desarrollos que han tenido lugar durante ese periodo en la teoría económica de que se suelen servirse los análisis del Fondo, "los economistas del FMI usan ahora un aparato analítico muy similar al usado por sus colegas hace 25030 años" (Edwards 1990, p. 614); es decir, muy similar al modelo de Polak. ${ }^{20}$ Seria igenúo

19. Meller (1987), Edwards (1990) y Buira (1983) ofrecen algunos detalles sobre cómo se implementa la PF en la práctica. Una fuente más directa es el trabajo de Robichek (1985).

20. Según Edwards (1990, pp. 623-29), el FMI habria sacado muy poco provecho de los desarrollos de la macroeconomia de la economia abierta, y en general de los de la teoría macroeconómica, que se han producido en los últimos treinta años. A este respecto, Edwards (1990, p. 623) señala que "El modelo básico del Fondo es fundamentalmente estático, tiene un sector financiero muy rudimentario, omite la existencia de incertidumbre, no le asigna un papel fundamental a las expectativas, y supone que el nivel del producto y del desempleo es exógeno y no se ve afectado por el programa. Más aún, este modelo no incluye formalmente cuestiones relacionadas con la naturaleza intertemporal de la cuenta corriente, el papel del riesgo y el autoaseguramiento en las elecciones de cartera, el papel de la congurencia temporal y de los compromisos previos en la política económica, la economia de los contratos y la reputación, la economía de los tipos de cambio de equilibrio, la 'crítica de Lucas', y la teoría de los ataques especultativos y las crisis de devaluación, para sólo señalar algunos de los avances recientes más importantes en la macroeconomia internacional". 
esperar que las consecuencias de este conservadurismo extremo no fueran adversos de cara a la mejora del diseño y de la eficacia de los programas del FMI. ${ }^{21}$

Las consenuencias, sin embargo, trascienden este terreno y tienen importancia también de cara a la consistencia del marco analítico de la PF con el conjunto de medidas que suelen incorporar los programas. Esto es particularmente evidente en el caso de la devaluación. Como se ha señalado arriba, en los primeros ańos de operación del Fondo habia un divorcio entre los programas que se implementaban a partir del marco de PF (para desequilibrios temporales) y los que descansaban en el ajuste del tipo de cambio (para desequilibrios fundamentales). De ahi que, como afirma Buira (1983), el marco de la PF no incluyera una "relación entre el tipo de cambio y los sectores monetarios y real de la economia". De ahi también que en la práctica haya sido frecuentes encontrar "devaluaciones como condición previa para la elaboración de un programa", y que sólo después de la devaluación se haga uso del marco de programación"en el que se suponen fijos los tipos de cambio para determinar esencialmente la permisible expansión monetaria" (Buira 1983, p. 126).

No debe de extranar en este contexto que el marco analítico del Fondo carezca de "un aparato térico completo, para ocuparse de dos cuestiones fundamentales relativas a la devaluación...primero, ¿cómo se determina el grado de sobrevaluación de una moneda? y, segundo, ¿cómo se decide el ritmo óptimo de ajuste del tipo de cambio sobrevaluado para llegar al de equilibrio?" (Ibid.). Las deficiencias de un enfoque que no es capaz de responder responder a tan cruciales interrogantes son obvias, y tienen mucho que ver con el desempeño en términos de eficacia de los programas del Fondo, así como con su excesiva generación de costos económicos y sociales.

\section{Algunos efectos "indeseables" de los programas de establliza- ción}

Independientemente de su capacidad para corregir los desequilibrio macroeconómicos mencionados, la implementación de los programas de estabilización del Fondo podrian producir una serie de efectos "indeseables". Por una parte, tedrian un impacto depresivo sobre el nivel de acti-

21. De hecho, según Edwards (1990, p. 624), "muchos de los nuevos desarrollos de la teoria de la política económica pueden enriquecer grandemente el marco de la política del Fondo y pueden traducirse en consejos más precisos, mejores y más eficaces" 
vidad económica y de empleo, en tanto que contraen la demanda agregada doméstica. Khan y Knight (1981, pp. 33-41), en una simulación realizada mediante un modelo macroeconómico para un buen grupo de paises subdesarrollados, encontraron que para generar una mejora de $50 \%$ en el nivel de reservas internacionales mediante la contración del crédito con un programa de estabilización normal (de 1 año de duración), el nivel de desempleo habría de aumentar en 5 puntos porcentuales. ${ }^{22}$ Resultados similares han sido encontrados por Porter y Ranney (1982) tanto en el caso de ajuste externo como en el del ajuste interno. Existen importantes razones para pensar que en los países subdesarrollados los programas del Fondo difícilmente podrian dejar de producir estos efectos.

El sesgo recesivo de los programas de estabilización está vinculado tanto a las políticas de contracción de la demanda agregada -como los recortes crediticios, por ejemplo- como a las que buscan incidir sobre los precios relativos -como la devaluación. Dadas las características de los sitemas financieros de los paises subdesarrollados, en los que se carece de un mercado de títulos valores desarrollado, la restricción del crédito en el mercado financiero formal reduce el financiamiento para inversión y capital de trabajo de las empresas, algunas de las cuales tienen que volcarse al segmento informal del mercado financiero, donde las tasas de interés, inicialmente muy superiores a las del segmento formal, se incrementan ante la mayor demanda. Así, en el corto plazo al menos, la producción tendería a caer tanto por el menor acceso al crédito (efecto demanda) como por su mayor costo (efecto oferta) (van Wijnbergen 1986). Alexander Segovia (1991) ha sefialado, y citado evidencia para América Latina, otro canal que alimentaria el sesgo recesivo de la políticas de contracción de la demanda agregada, el cual trascendería el corto plazo. Este canal se refiere a la contracción de la inversión privada a que darian origen los recortes en los gastos de capital del

22. Estos economistas, del FMI, han reconocido que un aumento del desempleo de esa magnitud impondría "una pesada carga en un pais subdesarrollado, tanto porque los ingresos son cercanos a niveles de subsistencia como porque es probable que el efecto empleo caiga desporporcionadamente sobre el incipiente sector industrial" (Khan y Knight, 1981, p. 43). En la práctica, sin embargo, el FMI parece haber cerrados sus ojos muchas veces a tales "perversidades". Como Taylor $(1989$, p. 37) ha señalado, "en lo que se refiere a austeridad, el artículo de té más importante del Fondo se refiere a que la restricción de la demanda no afecta la actividad económica. Provoca, más bien, que caigan los precios (por lo menos en el caso de los bienes no comerciables)". 
gobiemo, que con mucha frecuencia realizan los programas de estabilización, en tanto que existe una relación de complementariedad entre la inversión privada y la inversión pública.

La devaluación, por su parte, también generaria efectos recesivos de corto plazo, debido, entre otros factores, a que se traduce en un aumento en el nivel general de precios y contrae el acervo real de dinero de la economia, así como en tanto que vuelve más difícil la importación de insumos intermedios y bienes de capital, muchos de los cuales no son producidos en los paises subdesarrollados (Taylor y Krugman 1978; van Wijnbergen 1986). Por otra parte, en virtud de las diferencias en las porpensiones marginales a gastar, los efectos redistributivos que la devaluación suele generar en contra de los asalariados frente a los capitalistas, por una parte, y en contra del sector privado frente al sector público, por otra, tenderian también a contraer la demanda agregada y, de ese modo, a desacelerar la actividad económica en el corto pazo (Taylor y Krugman 1978).

Los programas de estabilización, por otra parte, generarian efectos regresivos en la distribución del ingreso, tanto mediante sus políticas macroeconómicas restrictivas como por la devaluación. En cuanto a la politica fiscal concierne, la reducción del gasto público tiende a afectar en la mayoria de los casos principalmente a los grupos de más bajos ingresos, que son los principales beneficiarios del gasto social realizado por el Estado, típico candidato al sacrificio en los programas de estabilización. Un efecto parecido tendria la adopción de una política crediticia restrictiva hacia el sector privado, en tanto que "la restricción del crédito en general tiende a sesgar el acceso a los recursos productivos disponibles en favor de las empresas grandes y bien establecidas (especialmente multinacionales) a expensas de empresas medianas y pequeñas", como también "en favor de los consumidores y productores ubanos y contra los rurales" (Johnson y Salop 1980, p. 11).

En cuanto a los efectos redistributivos perversos de la devaluación, teóricamente ésto es resultado de al menos dos factores: en primer lugar, de acuerdo con el enfoque de la absorción, la reducción del gasto interno exige que la propensión a gastar de la economia disminuya, lo cual está generalmente asociado a una redistribución del ingreso de los grupos de menores ingresos (con una propensión al gasto muy alta) hacia los grupos de más altos ingresos (con una menor propensión a gastar). Krugman y Taylor (1978) han sostenido que este será el caso en tanto que la devaluación cambiaria la distribución funcional del ingreso contra los asalariados. Esto es consistente con el principio, menos ieórico, de que, generalmente, para que la devaluación nominal se tra- 
duzca en una devaluación real y en una mejora en la competitividad de los bienes nacionales, los salarios reales tienen que caer (Ahamed 1986, Fischer 1986). ${ }^{23}$

En segundo lugar, el efecto de la devaluación es aumentar los precios relativos de los bienes transables. De acuerdo con un conocido postulado neoclásico (teorema Stolper-Samuelson), cuando el precio relativo de los bienes que usan más intensivamente capital aumenta, la remuneración a este factor (las ganancias) se incrementa, mientras que la remuneración al trabajo (los salarios reales) disminuye. $Y$ como los bienes transables serian en su conjunto más intensivos en capital que los no transables, la devaluación resdistribuirá el ingreso en favor del capital (Corden 1986; Ahamed 1986).

Asi, al margen de su efectividad para alcanzar los objetivos macroeconómicos que se proponen, existen fuertes razones para pensar, a priori, de que los programas de estabilización económica producen elevados costos económicos y sociales. Como veremos en la siguiente sección, la evidencia empirica existente no es capaz de negar esas presunciones "apriorisitcas". De ahi la enorme controversia que suele girar en torno a ellos y su escaza popularidad, particularmente entre los grupos sociales menos favorecidos, sobre cuyas espaldas cae siempre una parte desproporcionada de los costos que acarrean.

\section{La eficacla de los programas de establlización del Fondo}

Existen al menos cuatro criterios o enfoques para evaluar la eficacia de los programas de estabilización del FMI (Edwards 1990, pp. 629-31). Por una parte está el criterio positivo que se basa en la comparación de ciertas variables macroeconómicas clave antes y después del programa. Algunas evaluaciones basadas en este criterio hacen uso de técnicas estadisticas no paramétricas a fin de determinar si el cambio que se produce en las variables es o no significativo en términos estadísticos. Por otra parte, está el criterio normativo que se basa en la comparación de las metas del programa con los resultados logrados. Existe también el enfoque del grupo de control, que compara el comportamiento de ciertas variables macroeconómicas en paises con programa con su comportamiento en paises sin programa. Por último, está el criterio conjetural que compara los resultados del programa con el posible resultado

23. Ground (1984, p. 65) señala una caso en que puede lograrse una devaluación real sin que necesariamente los salarios reales caigan. Sin embargo. como el mismo Ground sostiene, este caso, aunque "es concebible", resulta "poco probable". 
de otro programa alternativo capaz de producir un ajuste similar. ${ }^{24}$

La mayoria de evaluaciones que se han realizados sobre la eficacia de los programa de ajuste del Fondo se ha basado en los tres primeros criterios. ${ }^{25} \mathrm{~A}$ continuación se revisan los resultados encontrados en algunas de tales evaluaciones en los paises subdesarrollados. Más adelante, en la segunda subsección, se examina la experiencia estabilizadora de El Salvador en la década de los ochenta, con el programa de 1982 y el de 1986, haciendo uso de los dos primeros criterios. Estas revisiones tienen caracteres diferentes. En el primer caso, se busca ofrecer los resultados globales de los programas de manera muy aislada. En el caso de El Salvador, se busca examinar con un mayor nivel de detalle, y teniendo en cuenta el contexto económico global salvadoreño, la eficacia y costos de programas de estabilización durante los ochenta. Esta desiguales revisiones comparten, sin embargo, un mismo propósito: plantear algunas hipótesis explicativas sobre los resultados de los programas de estabilización del Fondo.

\section{La experlencla de los paises subdesarrollados en general}

Desde su creación hace más de cuarenta años, el FMI ha jugado un rol muy activo en los paises subdesarrollados en los esfuerzos de estabilización económica. Con diversas, aunque no muy importantes, variantes el programa de ajuste del Fondo expuesto en la primera sección ha sido aplicado en una diversidad de paises en apuros económicos, algunas veces con el respaldo formal y financiero del organismo y otras sin él.

En los últimos años, una variedad de economistas - muchos de ellos pertenencientes al FMI - han realizado numerosas evaluaciones sobre la eficacia de los programas del Fondo. Estas evaluaciones no parecen dejar un buen sabor: aunque algunas veces los programas han sido eficaces, abundan los casos en que éstos apenas han logrado algunos de sus objetivos o han resultado en un completo fracaso. Cualquiera que haya sido el resultado en términos de estabilización, sin embargo, este ha implicado costos en términos de crecimiento, empleo y distribución del ingreso, muchas veces significativos.

El cuadro 1 resume la experiencia estabilizadora con el Fondo de una variedad de paises subdesarrollados en los últimos treinta ańos.

24. Cada uno de estos enfoques tiene sus propias limitaciones. Al respecto, véase nuevamente Edwards (1990) y Goldstein y Montiel (1986).

25. Véase Reichman y Stillson (1978), Kelly (1982), Beveridge y Kelly (1980) y Edwards (1990). 
Los datos parecen ser muy poco bondadosos con los programas del FMI: de los programas implementados entre 1963 y 1972, ni siquiera la cuarta parte habria alcanzados los objetivos de inflación y balanza de pagos; mientras que de los que se llevaron a cabo entre 1983 y 1985 un poco más de la mitad alcanzó la meta de cuenta corriente y un poco más del $40 \%$ la de inflación. Los resultados en términos de crecimiento habrian sido aún más pobres.

\section{Cuadro 1}

Resultados de los programas del FMI en diversos paises subdesarrollados

\begin{tabular}{lccc}
\hline $\begin{array}{l}\text { Resultado } \\
\text { Programas }\end{array}$ & & $\begin{array}{c}\text { Reichman y } \\
\text { Stillson* }\end{array}$ & Edwards** \\
\hline $\begin{array}{l}\text { Mejoró balanza de pagos } \\
\text { Cumplió meta cuenta corriente }\end{array}$ & $(\%)$ & 24 & - \\
$\begin{array}{l}\text { Redujo inflación } \\
\text { Cumplió meta de crecimiento }\end{array}$ & $(\%)$ & - & 52 \\
\hline
\end{tabular}

Fuente: Reichman y Stillson (1978) y Edwards (1990).

- Comprende 79 programas de estabilización implementados en el perlodo 1963-72.

* Comprende 34 programas implementados en 1983-85.

Otras evaluaciones resenadas por Edwards (pp. 630-33) sobre la eficacia de los programas del Fondo en las últimas tres décadas coinciden en términos generales con los resultados presentados en el cuadro 1. Edwards concluye que en general los programas producirian:

- un mejoramiento de la balanza de pagos global y de la cuenta corriente

- "una reducción ligera, aunque no necesariamente significativa, de la inflación"

- una contracción del producto en el corto plazo.

Un poco más especificamente, a juzgar también por la evidencia reseffada por Edwards (1990), el éxito de los programas ha tendido a ser mayor en lo que a la cuenta corriente se refiere; luego ha seguido la balanza de pagos global, y por último la inflación, donde los resultados raras veces han resultados ser "significativamente positivos". Prácticamente todas las evaluaciones revisada por Ewdars encuentran "una re- 
ducción significativa" del producto.

Debe sefialarse que abundan las situaciones en que las metas intermedias de los programas no se cumplen, ${ }^{26}$ y que ello explicaria en tales casos - al menos formal y parcialmente - el fracaso de los programas. Sin embargo, hay que sef́alar también que generalmente este incumplimiento no se debe al desinterés de las autoridades intemas por la estabilización, sino más bien a los problemas de aceptabilidad social y política de los programas, derivados de sus costos excesivos. Esto representa de suyo un problema importante. Aquí estamos interesados, sin embargo, en aquellos casos en que no obstante haberse cumplido con las metas intermedidas, los programas han fracaso total o parcialmente. Es para estos casos que es relevante la discusión de la tercera subsección.

\section{La experiencia de EI Salvador en los ochenta ${ }^{27}$}

Al igual que para muchos paises latinaoamericanos, la década de los setenta marcó para El Salvador el fin de una extraordinaria estabilidad económica y de un proceso de crecimiento que se había mantenido sin interrupción por varias décadas. Aunque la estabilidad económica habia desaparecido desde 1973, no fue sino hasta finales de la década (de los setenta) que la crisis económica asumió un carácter más profundo y generalizado. El estallido de esta crisis, en 1979, coincidió con la explosión de la guerra, en cuyo marco se ha desarrollado la actividad económica en los últimos doce años.

En 1979, simultáneamente con un aceleramiento de la inflación y un fuerte deterioro en la balanza de pagos, la producción nacional registró una caida por primera vez en décadas. Al iniciarse el decenio de los ochenta, la crisis económica no hizo sino agudizarse. La producción siguió cayendo inconteniblemente, la inflación y el desequilibrio externo continuaron en ascenso, mientras que el déficit fiscal como porcentaje del PIB creció considerablemente. Para 1981, el PIB habia acumulado una caida de $18.7 \%$, mientras que las reservas internacionales netas

26. Según datos presentados en Edwards (1990, p. 638), en 1983-85, en promedio, solamente alrededor del $30 \%$ de los programas del Fondo cumplieron su meta de déficit fiscal/PIB; el cumplimiento de las meta de crédito interno anduvo cerca del $50 \%$, y el del crédito interno neto al gobierno cerca del $60 \%$. En el estudio de Reichman y Stillson (1978), la proporción de casos en que el crédito interno y el crédito al sector público disminuyeron fue de $65 \%$ y $72 \%$, respectivamente (pp. 298-99).

27. A menos que se indique de otro modo, los datos usados en esta subsección provienen del Banco Central de Reserva de El Salvador, especialmente de su Revista Mensual. 
(RIN) habian disminuido en más de $\$ 280$ millones desde 1979 , y su nivel se habia vuelto altamente negativo. El déficit en cuenta corriente (excluyendo transferencias) y el déficit fiscal habian llegado a representar, respectivamente, el $8.2 \%$ y $9.4 \%$ del PIB; en tanto que la inflación se mantenia a un nivel cercano al $15 \%$. Esta situación obligó a El Salvador a unirse a las decenas de paises subdesarrollados que han tenido que embarcarse en un progrma de estabilización al estilo FMI, con o sin el apoyo formal de éste.

\subsection{El programa de establllzación de 1982}

Alarmadas por el incontenible deterioro económico iniciado en 1979, en 1982 las autoridades económicas salvadorefnas dieron los primeros pasos para tratar de enfrentar la crisis. En julio de ese año, el gobierno salvadoreño suscribió un convenio de crédito contingente y compensatorio con el FMl, a fin de implementar un programa de estabilización económica que duraria 1 año. En la mejor tradición de los programas de estabilización respaldados por el Fondo, el programa buscaba reducir la demanda agregada con el objeto de disminuir la inflación y mejorar la balanza de pagos. Se pretendia alcanzar estos objetivos fundamentalmente mediante la reducción del déficit fiscal, un mayor control del crédito, la flexiblización de la política cambiara y la elevación de las tasas de interés.

Referente al déficit fiscal, el programa se centró casi exclusivamente en una reducción del gasto, particularmente el vinculado con la inversión. No fue sino hasta 1983, cuando el periodo del programa estaba casi concluyendo que se adoptaron medidas para incrementar los ingresos tributarios. En cuanto a la flexibilización de la política cambiaria, ésta consistió en la creación de un mercado paralelo de cambios, que significó -aparte de una devaluación parcial de hecho- la adopción de un régimen de tasas de cambio múltiples. ${ }^{28}$ Como parte de sus esfuerzos para atacar el desequilibrio externo, las autoridades económicas implantaron también restricciones comerciales cuantitativas (incluyendo prohibiciones) y cambiarias (depósitos previos y asignación de divisas de acuerdo a ciertas prioridades) a las importaciones. En lo que se refiere a las tasas de interés, el objetivo era volverlas positivas en términos reales a fin de estimular el ahorro financiero doméstico y frenar la fuga de capitales. Sin embargo, a pesar del aumento de las tasas nominales, las tasas reales continuaron siendo altamente negativas.

28. Para un examen exhaustivo del funcionamiento del mercado de cambios y sus resultados, véase Carolina de Franco (1990). 
Si comparamos los valores iniciales de las variables que constituyen las metas finales de los programas del Fondo sus valores posteriores (criterio positivo), puede decirse que el programa no fue muy eficaz, a pesar de que las variables que constituyen las metas intermedias mejoraron notablemente. Aunque para 1983 el déficit fiscal ${ }^{20}$ como proporción del PIB se redujo en más de 3 puntos porcentuales y el crecimiento del crédito interno al sector público fue altamente negativo, la inflación se incrementó levernente, impulsada por la devaluación y las expectativas. Por su parte, la cuenta corriente ${ }^{30}$ de la balanza de pagos como proporción del PIB se redujo significativamente, gracias a una fuerte reducción de las importaciones. La balanza de pagos global también mejoró, pero por razones exógenas. En efecto, el crecimiento registrado en el nivel de reservas internacionales obedeció fundamentalmente a un incremento sustancial en la asistencia económica norteamericana. En realidad, de no haber sido por la asistencia de la AID, en 1982-83 El Salvador habria perdido reservas por más de $\$ 145$ millones y se habria desatado una verdadera crisis cambiaria.

En el marco de una precaria situación político-militar, de tasas de interés reales negativas y de fuertes expectativas de devaluación, la fuga de capitales continuó, si bien a niveles bastante inferiores a los de 1979-80. Evidentemente, ésta disminución de la fuga de capitales se explica mucho más por el hecho de que en 1983 quedaban ya muy pocos capitales por sacar del pais, que por las medidas de politica económica adoptadas por las auotoridades, sobre todo si se tiene en cuenta el contexto político-militar imperante ese año.

Cabe senalar, por otra parte, que pese a las medidas de estabilización, la economia salvadoreña registró en 1983 un leve crecimiento. En este resultado habria tenido mucho que ver tanto el incremento de la ayuda económica norteamericana y de las remesas de salvadoreños en el extranjero, como el hecho de que el régimen cambiaro favorecia la importación de materias primas y bienes de capital. Tales factores hicieron posible que el volumen de importacion de estos bienes no se viera prácticamente afectado por el programa de estabilización. Esto, aunado

29. El concepto de déficit fiscal con el que trabajamos corresponde al déficit del gobierno central, del que, por otra parte, se han excluido las donanciones externas

30. En virtud de la naturaleza de las transferencias y su gran importancia en el sector externo salvadoreño, el concepto de "cuenta corriente" que hemos preferido usar para El Salvador corresponde en realidad a la balanza de bienes y servicios. Excluye, por lo tanto, las transferencias oficiales y privadas, que de esa manera pasarian a formar parte de la cuenta de capital. 
a un mediano repunte de las exportaciones, gracias a un incremento del precio mundial del café, permitió que la actividad económica no se siguiera contrayendo. Dos puntos merecen ser resaltados en estos resultados.

Por una parte, si partimos de la aceptación de una relación entre el comportamiento de la actividad económica y la importación de bienes intermedios y de capital, pareciera que algún elemento de selectividad en la estabilización resulta positivo de cara a paliar los efectos recesivos de corto plazo provocados por el ajuste externo. Si el minimizar el impacto recesivo de corto plazo - sin sacrificar necesariamente el objetivo global de balanza de pagos - fuera una prioridad, esto sugeriria cierta superioridad de los instrumentos de política comercial sobre los de política cambiara, dado el carácter más selectivo de los primeros. Sin embargo, no debe olvidarse las dificultades administrativas (y por tanto de eficacia en la práctica) y los efectos perversos en la asignación de recursos que el uso permanente de instrumentos de política comercial con fines de balanza de pagos puede ocasionar.

Por otra parte, los resultados parecieran indicar que cuando se dispone de recursos externos, los riesgos de que la implementación de un programa de estabilización tenga un impacto recesivo fuerte en el corto plazo serian mucho menores. En el caso de El Salvador, las remesas y la asistencia de la AID resultaron cruciales en 1983 (en realidad a lo largo de toda la década). Sin embargo, hay que senalar también que la disponibilidad de recursos puede generar complacencia y contribuir a la postergación indebida de posiciones externas no sostenibles en el mediano o largo plazo.

Haciendo un balance, podriamos decir que la eficacia en términos macroeconómicos de las medidas de política económica adoptadas en 1982-83 habria sido bastante pobre: en términos del desequilibrio interno, no lograron controlar la inflación; en términos del desequilibrio externo, si bien la cuenta corriente mejoró, si se excluye la asistencia de la AID de las entradas de capital, ${ }^{31}$ no se consiguió frenar el deterioro de la balanza de pagos global. En realidad, en el marco de la guerra, el hecho de que la economia en general siguiera manteniéndose al borde del precipicio y no cayera aún en él, obedeció fundamentalmente a los exhorbitantes volúmenes alcanzados por las transferencias del exterior.

El impacto en el terreno económico-social habria sido sin duda ad-

31. Recuérdese que, por la definición de cuenta corriente que estamos usando, la asistencia de la AID formaria parte de la cuenta de capital. Véase la anterior. 
verso. En el periodo $1982-83$ los salarios reales en el sector privado habrian caido en cerca de un $5 \%$, mientras que en el sector público la calda fue de más del $12 \%$ (FMI 1985, p. 67). Si tenemos en cuenta que la tasa media anual de crecimiento en el bienio fue de $-2.4 \%$, el impacto sobre la distribución del ingreso fue claramente regresivo, con los asalariados dismuyendo su participación en el producto. El largo congelamiento salarial que estuvo vigente en los primeros ańos de los ochenta tuvo mucho que ver con este resultado.

El programa de estabilización concluyó formalmente y de hecho en 1983. En 1984, las autoridades habrian perdido bastante control sobre el déficit fiscal, que, impulsado en gran medida por el incremento en los gastos de defensa, ascendió de nuevo a 9.4\% del PIB. No obstante la inflación se redujo levemente ese ano; es decir, los precios se comportaron exactamente al revés de lo que los teóricos de los programas de estabilización habrian pronosticado. La expansión de la demanda y el que se hubiese devaluado muy poco ese ano no parecen estar desvinculados del hecho de que la producción creciera en un $2.3 \%$.

En 1985, el panorama económico se deterioró notablemente. Por una parte, la inflación alcanzó el nivel —entonces récord- de $22.3 \%$; mientras que, por otra, el déficit en la cuenta corriente de la balanza de pagos llegó a representar el 9.5\% del PIB. Es decir, la inestabilidad económica se agravó. Esto en el contexto de una devaluación mucho más fuerte y de una drástica reducción del déficit fiscal, que descendió a sólo $2.3 \%$ del PIB.

El comportamiento de la inflación en este período 1982-85 sugiere que la dinámica de los precios parece haber respondido mucho más a la evolución ascendente del tipo de cambio nominal que a las presiones derivada del déficit fiscal. Por otra parte, la dinámica de la cuenta corriente de la balanza de pagos habría estado más asociada al comportamiento de la actividad económica interna en general que al del déficit fiscal en particular. La cuenta de capital, por su lado, habria resultado más asociada a la evolución de la situación política interna y otras variables exógenas que a variables de política económica interna.

\subsection{El programa de establlización económica de 1986}

La poca eficacia de las políticas adoptadas durante 1982-85 y el agravamiento infrenable de los desequilibrios interno y externo, condujo a las autoridas a embarcarse en un nuevo plan de estabilización en 1986. A diferencia del programa de 1982, éste habria de ejecutarse en un periodo de 3 años. 
Cuadro 2

Princlpales medidas contenldas en el plan de establilzación 1986

\begin{tabular}{ll}
\hline Area & Medidas \\
\hline Fiscal & $\begin{array}{l}\text { Creación de impuesto sobre ingresos extraordinarios por } \\
\text { exportación de café, creación de impuestos selectivo al } \\
\text { consumo, reformas al impuesto sobre la renta. }\end{array}$ \\
Monetario- & $\begin{array}{l}\text { Reducción de crédito BCR al gobiemo de } 215 \text { a } 100 \text { millo- } \\
\text { nes, reducción de crecimiento oferta monetaria y crédito } \\
\text { en } 3 \text { y } 7 \text { puntos porcentuales respectivamente, incremento } \\
\text { de tasas de interés y tasa de redescuento, incremento ta- } \\
\text { sa de encaje legal. }\end{array}$ \\
Cambiaria & $\begin{array}{l}\text { Unificación cambiaria con una devaluación formal de } \\
100 \% \text { y una efectiva de } 32 \% \text { (Rivera y Saca 1987), ajuste } \\
\text { periódicos al tipo de cambio. }\end{array}$ \\
Comercial & $\begin{array}{l}\text { Reforzamiento de restricciones cuantitativas, prohibicio- } \\
\text { nes, depósitos previos de } 100 \% \text { sobre valor de las impor- } \\
\text { taciones } \\
\text { Incremento de salarios minimos en } 60 \% \text { en el agro y 15- } \\
18 \% \text { en otros sectores, incremento de } 150 \text { colones men- } \\
\text { suales en salarios de trabajadores gubernamentales. } \\
\text { Congelamiento de precios de la canasta básica, incremen- } \\
\text { to de subsidio a transporte público de pasajeros. }\end{array}$ \\
Precios &
\end{tabular}

El nuevo programa, bastante más completo que el de 1982, no contó con el respaldo del FMI sino con el de la AID. Pese a contener algunas medidas atipicas de los programas del Fondo, el programa seguia básicamente la tradición de éstos. En el cuadro 2 se presentan las principales medidas adoptadas como parte del plan. No carece de interés señalar que la reducción del déficit fiscal no constituia en realidad un objetivo -y menos una prioridad- dentro del programa. De hecho, la meta de déficit fijada para 1986 implicaba un incremento de casi $70 \%$ con relación al déficit del año anterior. Esto no es muy sorprendente si se tiene en cuenta que en 1985 el déficit fiscal habia sido disminuido a sólo 2.3\% del PIB. Si era un objetivo la reducción de su financiamiento por el Banco Central, elemento central en el modelo del del Fondo, sobre todo de cara a la reducción de la inflación.

Es importante sefialar que este programa se implementa en un con- 
texto internacional bastante favorable, caracterizado por una baja en las tasas reales de interés en el mercado financiero mundial, una disminución de los precios del petróleo, una sustancial alza en los precios internacionales del café y una economla mundial mucho más dinámica. El contexto interno, sin embargo, seguia siendo altamente desfavorable, con la persistencia de la guerra y una insurgencia dispuesta a hacer fracasar el plan.

Las discrepancias ideológicas entre los grandes empresarios y el gobiemo, y el espíritu poco concertador de aquéllos, se convertía en otra restricción interna importante a las posibilidades del programa. Con todo, sin embargo, el clima político prevaleciente internamente parecía menos incierto que en 1982-83. Por otra parte, luego de más de siete años de guerra, el sector privado parecia haberse acomodado bastante al adverso contexto político-militar. De esta manera, puede decirse que el marco general en que el nuevo programa de estabilización era echado a andar, era menos adverso que el de su predecesor.

\subsubsection{El Impacto económico del programa}

Con relación al ajuste externo, dado que la demanda agregada doméstica no se redujo en 1986, a primera vista pareciera que la unificación cambiaria -que se tradujo en una depreciación real del colón en cerca de un $15 \%$ - y las mayores restricciones a las importaciones habrian sido las únicas medidas responsables de los resultados bastante favorables en la cuenta corriente de la balanza de pagos en el primer año del programa. En efecto, pese a que el gasto real se incrementó, la relación déficit en cuenta corriente sin donaciones/PIB fue disminuida en más de 3 puntos, y los objetivos que en ese rubro habian sido trazados fueron inclusive sobrepasados con bastante comodidad. No parece estar del todo claro, sin embargo, si estos resultados obedecieron más a las medidas de política adoptadas por las autoridades económicas o a la coyuntura sumamamente favorable que se presentó en los mercados internacionales -particularmente en lo referente a términos de intercambio-, aunque no puede negarse la influencia de ninguno de ellos.

Del lado de las exportaciones, la unificación cambiaria no habria sido un factor importante. El aumento que tuvo lugar en su valor se debió exlusivamente a una mejora en el precio internacional del café, cuya producción no sólo no es suceptible de cambiar significativamente en un ano en respuesta a una mayor rentabilidad, sino que estaba ya dada antes de que el programa de estabilización fuera puesto en marcha. Las exportaciones más suceptibles de ser influenciadas en el corto plazo (en este caso uno año) por una devaluación real de la moneda se mantuvieron en su conjunto prácticamente inalteradas. 
Del lado de las importaciones, sin embargo, las medidas de estabilización parecen haber sido más efectivas, aunque a primera vista la evidencia no pareciera muy clara. Por un lado, tenemos que las importaciones de bienes de consumo, las más sensibles ante alteraciones en el tipo de cambio real, se redujeron muy poco con relación al año anterior. Esto no resulta extraño, pues la devaluación afectó relativamente poco a estos bienes en la medida en que el grueso de sus importaciones era financiado ya en el mercado negro o en el mercado paralelo (bancario) a un tipo de cambio que en promedio difería muy poco del que entró en vigencia con la unificación cambiaria.

Por otro lado, contario a lo esperado, las importaciones de bienes de capital - favorecidas relativamente por el régimen cambiario anterioraumentaron significativamente en 1986. Esto fue impulsado fundamentalmente por el incremento en las importaciones de bienes de capital para el sector transporte, a los cuales se habia eximido por completo de impuestos a la importación. La importaciones de bienes intermedios, por su parte, cayeron de manera sustancial, algo perfectamente esperable, pues este tipo de importaciones fue el más favorecido por el régimen de tasas de cambio múltiples y por tanto el más afectado por la unificación cambiaria. En realidad, fue la contracción en las importaciones de bienes intermedios y, sobre todo, una sustancial reducción de las importaciones de servicios lo que hizo caer en 1986 las importaciones totales.

La mejora en la cuenta corriente no se tradujo, sin embargo, en una mejor posición de la situación externa global del país. La cuenta de capital, que en 1985 habia arrojado por primera vez en la década un saldo favorable, se deterioró considerablemente en 1986, empujada fundamentalmente por la fuga de capitales. Aunque las autoridades monetarias habian alcanzado su meta de incrementar el nivel de reservas internacionales en $\$ 75$ millones, su logro fue totalmente espúreo: lo que la posibilitó fue una revalorización del oro por $\$ 91$ millones. De hecho, pues, las reservas internacionales cayeron.

Al margen de su contribución a por lo menos que la posición del sector externo no se deteriora apreciablemente, la unificación cambiaria tuvo sus costos en términos de crecimiento económico y, sobre todo, en términos de inflación. En efecto, la tasa de crecimiento económico en 1986 de apenas $0.6 \%$ (1.4 punto porcentual inferior a la de 1985). Aunque no habria que ignorar el papel de la destrucción que el terremoto de 1986 causó en la capital salvadoreña, este menor crecimiento estuvo muy vinculado a los problemas causados por la disminución de la importación de bienes intermedios, que golpeó particularmente a la agricultura y la industria manufacturera, los dos sectores más importantes de la economia salvadoreña. 
La inflación, por su parte, alcanzó en 1986 el nivel más alto registrado en la historia económica salvadoreña (31.9\%). Factores monetarios y el crecimiento de los salarios nominales habrian tenido que ver algo con ésto, aunque quiza haya sido la devaluación el factor más importante, no sólo por la medida en si, sino también por el reforzamiento de las expectativas inflacionarias que significó. En cuanto a los factores monetarios, cabe señalar que el Banco Central pareció haber aflojado las riendas de la liquidez al permitir una expansión de la oferta de dinero de casi un $30 \%$, doce puntos arriba de la meta establecida. Los salarios nominales, por su parte, habrian crecido por encima del 15\% en 1986 (FMI 1990).

El aflojamiento de la liquidez, sin embargo, no tuvo nada que ver con el financiamiento del déficit fiscal por el Banco Central, que en en 1986 fue negativo por más de 300 millones de colones, superándose con gran holgura la meta establecida. Esto a pesar de que el nivel del déficit fiscal fue ampliamente superior al que habia sido programado, aunque relativamente bajo con relación al PIB. La expansión monetaria se derivó más bien del incremento del crédito al sector privado en más del $19.2 \%$ con relación al año anterior. La fuerte expansión de los medios de pago generada en algunos meses por las entradas extraordinarias de divisas por exportaciones de café no fueron ajenas al fenómeno. Las medidas del Banco Central de incrementar la tasa de redescuento en dos puntos y el coeficiente de encaje legal en cinco durante ciertos periodos, habrian sido insuficientes para frenar la expansión de la liquidez.

En cuanto al efecto de la devaluación sobre los precios, éste parece estar fuera de discusión, sobre todo si se considera el alto grado de apertura de la economia salvadoreña y su elevada dependencia de la importación no sólo de bienes intermedios y de capital, sino también de una gran variedad de bienes de consumo. ${ }^{32}$ A esto habria que añadir el impacto de la medida en el reforzamiento de las expectativas de inflación, que para 1986, luego de 13 años de tradición inflacionaria, habia pasado a constituir un componente importante de la inflación en El Salvador. Esta variable, sin embargo, no parece haber sido una preocupación en el programa.

En términos generales, aún desde una óptica macroeconómica, el balance para el primer año de implementación del "Programa de Estabilización y Reactivación Económica" no pareció ser muy favorable. Su

32. Estimaciones econométricas han establecido que en El Salvador si el tipo de cambio aumenta en $10 \%$, los precios aumentarán en aproximdamente $4 \%$; una relación bastante similar existiria entre precios y expectativas inflacionarias (Rivera 1988, p. 26). 
impacto sobre el sector externo no habria sido tan positivo, como el examen aisaldo de la cuenta corriente de la balanza de pagos podria sugerir; sus costos en términos de desaceleración del crecimiento economómico no fueron desedenables; mientras que sus efectos sobre el nivel general de precios fueron sumamante negativos, tanto que precipitaron al pais a un nivel récord de inflación. Todo ésto a pesar de que el - programa contó con el contexto internacional más favorable para EI Salvador en el decenio de los ochenta. Sin embargo, no debe olvidarse que el contexto interno continuó siendo adverso - con una intensa guerra y un sector privado bastante hostil hacia el gobiemo- y algunas de las metas intermedias del programa no se cumplieron.

Por otra parte, preocupadas por lo negativo del impacto socio-económico del programa durante el primer año y por los elevados costos políticos que ello significaba, así como por la precaria situación generada por el terremoto de 1986 para grandes contingentes de población en la capital, las autoridades económicas renunciaron a continuar aplicando algunas medidas contenidas en el programa original, particularmente en el área cambiaria. En efecto, contrario a to que habian anunciado a principios de 1986, las autoridades económicas se negaron a realizar ajuste alguno al tipo de cambio, a pesar de que la inflación registrada en El Salvador en ese año fue ampliamente superior a la de sus principales socios comerciales, algunos de los cuales -como Costa Rica - venian devaluando constantemente su moneda. El resultado fue que la moneda comenzó a revaluarse nuevamente en términos reales.

Sin embargo, la renuncia a continuar devaluando, junto a un control monetario mucho más estricto, se tradujo en en una caida de la inflación a $24.9 \%$ en 1987 y a $19.8 \%$ en 1988 . Al parecer, las autoridades tomaron muy en serio el rol jugado por la expansión monetaria en el aceleramiento de la inflación en 1986, y en 1987-88 optaron por seguir una política monetario-creditica sumamente restrictiva. ${ }^{33}$ El crédito del Banco Central al gobierno, por su parte, fue prácticamente insignificante en el bienio, concordante con una leve reducción del déficit fiscal como proporción del PIB. El resultado de esta política habria sido un crecimiento de menos de $10 \%$ en la oferta monetaria, lo que significó una caida en términos reales de cerca de $12 \%$; el crédito se habría expandi-

33. Aparte de otras medidas restrictivas, a fin de controlar la liquidez interna el Banco Central incluso obligó a los bancos a que colocaran cierta proporción de los depósitos captados en bonos de estabilización. Los bancos comerciales e Hipotecario invirtieron en junio el $1 \%$ de los depósitos y en septiembre el $2 \%$ en bonos de estabilzación. Las compras de bonos por parte de los bancos ascendieron a 242.6 millones de colones (BCR 1987, p. 31 ). 
do a una tasa promedio de alrededor de $17 \%$, contrayéndose en más de un $5 \%$ en términos reales.

Resulta bastante sorprendente que a pesar de 10 restrictivo de la política monetario-crediticia, el PIB haya crecido en $2.7 \%$ y $1.6 \%$ en 1987 y 1988, respectivamente. La disponibilidad de recursos externos arma de doble filo- apareceria nuevamente como factor importante en la reducción de los efectos recesivos del ajuste. En efecto, la desempeño en términos de crecimiento en esos años habria estado muy asociado al hecho de que las donacionaes internacionales aumentaran considerablemente a raiz del terremoto de 1986 , contribuyendo a una extraordinaria expansión de la construcción, que en 1987-88 creció a una tasa promedio superior a $8 \%$. Las actividades de reconstrucción en el sector público habrian contribuido a que la administración pública creciera en un $3.7 \%$. Por otro parte, debido en buena medida a la relativa abundancia de recursos externos, la devaluación estuvo ausente en 1987-88. El carácter restrictivo de la política monetario-creditica no habria afectado adversamente la actividad manufacturera, que en ese periodo experimentó su crecimiento más elevado en la década; pero si al, cuantitativamente más importante, sector agropecuario, que cargó con buena parte de las consencuencias de esa política.

Los logros relativos en términos de inflación y crecimiento tuvieron, sin embargo, su costo: la profundización del desequilibrio externo. En efecto, si bien la renuncia a seguir devaluando relajó las presiones inflacionarias y el estrangulamiento externo (acceso a bienes intermdios y de capital) de la economia, la sobrevaluación de la moneda y una fuerte caida de los términos de intercambio, profundizaron el deterioro de la balanza de pagos. En 1987-88, la relación saldo balanza de bienes y servicios/PIB se habria elevado en más de 2 puntos porcentuales con relación a 1986. En 1988, por primera vez desde 1981, el pais perdió reservas internacionales, esta vez por $\$ 64$ millones. En este contexto, sólo la asistencia económica norteamericana y las remesas de salvadorefios en el exterior habrian evitado el colapso de la balanza de pagos y una aguda desestabilización del mercado cambiario. De hecho, de no haber sido por esas transferencias, El Salvador habria agotado por completo sus reservas internacionales.

En resumen, el balance del impacto macroeconómico del programa de estabilización y reactivación económica no parece ser en general muy favorable, aunque tampoco parece ser desastroso. En ello tendria mucho que ver la relativa abundancia de recursos externos en El Salvador, que permite tener, simultáneamente, una balanza comercial altamente deficitaria y una balanza de pagos global, si no siempre supera- 
vitaria, no crítica. Si tomamos como punto de referencia $1984-85$, resulta que en 1986-88, si bien la cuenta corriente (como proporción del PIB) habria mejorado levemente, la inflación se habria incrementado y el crecimiento de la economia se habria desacelerado. No obstante, y a diferencia de otros paises latinoamericanos menos afortunados en términos de disponibilidad de recursos externos, no se llegó a una sitaución macroeconómica caótica.

Más significativo, al parecer, habria sido el impacto económico-social de los esfuerzos de estabilización, el cual se reflejó tanto en la caida de los salarios reales y los cambios consiguientes en la distribución factorial del ingreso, como en un incremento significativo en los niveles de pobreza. En efecto, en el periodo 1986-88, a juzgar por datos del FMI, los salarios reales habrian caido a una tasa media anual superior al $12 \%$ (FMI 1990). Puesto que en ese periodo se registró un crecimiento medio anual de casi $1.5 \%$, la distribución del ingreso se habria alterado significativamente en contra de los asalariados.

En este contexto, no deja de resultar un tanto curioso que, al menos en el área urbana, la distribución personal (o familiar) del ingreso prácticamente no se haya alterado: la participación del primer quintil en el ingreso habria cambiado de $5.6 \%$ a $5.5 \%$ entre 1985 y 1988 , mientras que la del último quintil de $42 \%$ a $43 \%$ (FUSADES 1989; MIPLAN 1990). Hay que tener en cuenta, sin embargo, que estos datos no incluyen el impacto sobre la distribución del ingreso provocado por la contracción del gasto social, que, como los mismos economistas del FMI (Johnson y Salop 1980) han reconocido, afecta predominantemente a los grupos de más bajos ingresos.

La pobreza habria aumentado en este periodo de manera significativa, al menos en los sectores urbanos: la proporción de familias urbanas pobres creció de $47.3 \%$ en 1985 a $67.3 \%$ en 1988 (FUSADES 1989). Si recordamos, con los economistas del FMI (Johnson y Salop 1980), que el impacto redistributivo adverso de los programas de estabilización es mayor en la áreas rurales, ${ }^{34}$ el incremento de la pobreza a nivel nacional en ese periodo pudiera muy bien ser mayor de lo que los datos sobre pobreza urbana sugieren. ${ }^{35}$

34. Véase supra, p. 580.

35. En estas circunstancias, el que no haya ocurrido un estallido social en EI Salvador se debería en buena medida al voluminoso flujo de remesas familiares, que favorece primordialmente a los ingresos de los sectores más pobres y que los datos de las encuestas de hogares en que se basan las cifras anteriores no captan. 
Ahora bien, seria incorrecto atribuir este deterioro económico-social exclusivamente a los esfuerzos de estabilización, e ignorar el papel de la dinámica "natural" del sistema económico-social salvadoreño. Sin embargo, también seria incorrecto negar que tales esfuerzos han jugado un rol importante en ello, aún teniendo en cuenta que el producto per cápita cayó ligeramente en el periodo en cuestión; el considerar esto último no cambia (al menos fundamentalmente) el problema, en parte porque tal caída no puede desvincularse de los esfuerzos de estabilización.

\section{Algunas hipotesis en torno a la eficacia establlizadora de los programas del FMI}

Los resultados de la experiencia estabilizadora de El Salvador en los ochenta concuerdan bastante con los obtenidos en otros paises subdesarrollados con programas del Fondo en las últimas tres décadas. En efecto, los exámenes concuerdan en que en los programas de estabilización: i) parece ser relativamente más fácil el mejoramiento de la cuenta corriente de la balanza pagos; ii) la disminución de la inflación es una tarea mucho más difícil, y raras veces exitosa; y iii) tal como se sugirió en la segunda sección, los efectos contractivos sobre la actividad económica están presentes casi siempre. Por otra parte, el examen de la experiencia salvadoreña sugiere que, en el caso de este pais al menos, los programas habrian contribuido a que la distribución factorial del ingreso se volviera más regresiva, $y$, debido en parte a ello y a los efectos recesivos, a que la pobreza se incrementara.

En esta subsección tratamos de plantear algunas hipótesis explicativa en torno a los resultados de los programas del Fondo, o de programas similares (caso de El Salvador 1986), en términos de su eficacia estabilizadora. También se ofrecen algunas hipótesis sobre los costos de los programas en términos de recesión, aunque estas últimas son más bien una reafirmación de los planteamientos presentados en la segunda parte.

Como se sabe, los programas del Fondo descansan en gran medida en dos intrumentos para tratar de lograr sus objetivos: la contracción del crédito (más en general, la contracción de la demanda agregada) y la devaluación. En lo que a balanza de pagos se refiere, en el corto plazo estos instrumentos inciden ambos en forma positiva sobre la cuenta corriente. En el caso del crédito y en general de las políticas de demanda agregada, buena parte de su efecto está asociado a la contracción que se provoca en la actividad económica. En el caso de la devaluación, parece ser que, pese a su impacto inflacionario, las devaluaciones nominales de la moneda casi siempre se traducen en devaluaciones reales, y 
que el efecto positivo sobre el tipo de cambio real no se erosiona tan rápidamente. ${ }^{36}$ Este suele más el caso mientras mayor control se ejerza sobre la demanda agregada (Edwards 1988).

El efecto favorable sobre la cuenta corriente suele lograrse principalmente disminuyendo las importaciones de bienes. Esto sugiere que la demanda de importaciones tiene una elasticidad ingreso y una elasticidad precio distintas de cero (no es completamente inelástica). Por otra parte, una incidencia significativa de la devaluación sobre las exportaciones en el corto plazo parece ser más difícil -y más difícil todavia por parte de las políticas de contracción directa de la demanda agregada-. particularmente en aquellos casos en que éstas son muy poco elásticas o en aquellos en que los bienes con una mayor elasticidad se destinan fundamental o totalmente al mercado interno. En este último caso en especial, debido sobre todo al efecto contractivo de las políticas de demanda agregada, los programas de estabilización, a pesar de la devaluación real, podrian (en el corto plazo) incluso tender más a contraer la producción que a incrementar las exportaciones. La razón de la escaza respuesta de las exportaciones en el corto plazo, pese al aumento del tipo de cambio real, estaría vinculada, por lo tanto, a factores de naturaleza estructural.

La otra parte de la balanza de pagos (la cuenta de capital) parece ser más independiente del manejo de los intrumentos fundamentales de los programas de estabilización. En realidad, en los paises subdesarrollados, la entradas netas de capital parecen ser una variable bastante exógena. No es otro, por cierto, el tratamiento que la variable recibe en el modelo de programación financiera del Fondo. ${ }^{37}$ Parece que ni el enfoque monetario de la balanza de pagos ni los modelos de flujos y de activos parecen ofrecer en general una respuesta satisfactoria al comportamiento de la cuenta de capital en estos países, sobre todo en el marco de la estabilización económica. ${ }^{38}$ En este marco, la cuenta de ca-

36. Véase Edwards (1988, cuadro 1, pp. 36-7). En este trabajo, Edwards examina 28 episodios de devaluación, y en 24 de ellos transcurrieron por lo menos 3 años antes de que el efecto de la devaluación sobre el tipo de cambio real se disipara. En el caso de la devaluación de El Salvador de 1986, habrian trancurrido al menos un año antes de que la inflación interna hiciera desaperecer el efecto sobre el tipo de cambio real (Véase Alexander Segovia 1989, cuadro 7).

37. Véase Meller (1987) o Edwards (1990).

38. El enfoque de flujos explica los movimientos internacionales de capital básicamente a partir de los diferenciales entre tasas internas e internacionales de interés y a partir de la devaluación esperada del tipo de cambio. El 
pital seria más sensible a la credibilidad en el éxito de los programas antiinflacionarios y al grado de certeza de que no habrán nuevas devaluaciones, así como a los vaivenes políticos internos. Si los programas tienen problemas de credibilidad y/o se prevee que la política cambiaria no es sostenible, o si hay incertidumbre-inestabilidad política, los diferenciales de tasas de interés (enfoque monetario y modelo de flujos), parecen ser menos relevantes. Bajo circunstancias normales, tales diferenciales y las expectativas de devaluación serian mucho más importantes, al menos con relación a los flujos privados de capital. Los flujos oficiales seguirán siendo fundamentalmente exógenos.

En general, en los paises subdesarrollados resulta dificil hacer generalizaciones sobre el comportamiento de la cuenta de capital; éste depende de las circunstancias particulares de cada país. En algunos casos, el servicio de la deuda (en el caso de los paises altamente endeudados estos es muy plausible; en ese caso, los programas ni siquiera se proponen mejorar la cuenta de capital) puede una variable explicativa importante. Este ha sido el caso, por ejemplo, de los paises latinoamericanos altamente endeudados en la década pasada. La facilidad de acceder a los mercados financieros internacionales suele ser otro factor explicativo. En otros casos, la fuga de capitales puede ser un factor importante, sobre todo si hay incertidumbre política; el algunos de estos casos, como se acaba se sefalar, los diferenciales de tasas de interés y las expectativas de devaluación serian factores explicativos importantes.

¿Por qué los resultados son menos "exitosos" con relación a la inflación? Nuestra hipótesis es que, de cara a este objetivo, el programa del Fondo no es muy coherente internamente, y que, como resultado de su reduccionismo en su explicación, parte de un diagnóstico muy pobre sobre las causas de la inflación, que se traduce en un también pobre disefio. En cuanto a la coherencia ${ }^{39}$ políticas necesarias para corregir el desequilibrio externo, como la devaluación, tienden a agravar la inflación, aún cuando otras, un mayor control del crédito, pudieran contribuir a disminuir ambos desequilibrios. En materia de inflación, por lo tanto, lo que los programas pueden hacer con la contracción del crédito pueden deshacerlo con la devaluación.

enfoque de activos plantea que el comportamiento de la cuenta de capital responde a las decisiones de asginación de cartera. Una exposición de estos dos enfoques puede enontrarse en Arellano (1986), McKinnon (1981) y Meller (1987).

39. Este puede ser un factor más importante en los resultados que se derivan del enfoque positivo. 
En el estrecho marco teórico del Fondo, el resultado global depende de cuál de esos dos efectos predomina. Ahora bien, pareciera que cuando hay una tradicción inflacionaria, las expectativas tienden a hacer que predomine el efecto de la devaluación, puesto que cuando un programa contiene medidas que aumentan el nivel de precios y otras que pueden reducirlo es más probable que el público preste mayor atención a las primeras y no espere una menor inflación, y contribuya asi a que sus expectativas se realicen. Con esa combinación de políticas, en general, ese sería el resultado más probable, a menos que en el país se haya perdido prácticamente todo control de los agregados monetarios y la inflación sea demasiado alta (una hiperinflación o algo cercano)..$^{.0}$

Resulta difícil establecer hasta qué punto los programas del Fondo, con su preocupación por el efecto precios relativos de la devaluación, toman en consideración en su meta de inflación el impacto de la devaluación -aunque serla ingénuo pensar que, ingenúamente, lo ignoran-, impacto que se torna aún más importante cuando el fenómeno inflacionario porta un fuerte componente inercial. ${ }^{41}$

El problema, sin embargo, tiende a tener una mayor complejidad que el reduccionismo del Fondo no capta. El Fondo atribuye la inflación a un exceso de demanda creado por factores monetarios y hace caso omiso de la inflación por costos o de la inflación estructural. ${ }^{42}$ El papel de las expectativas y la inflación inercial también están dusente en esa visión.

40. En los casos de inflaciones sumamente altas, por otra parte, las devaluaciones suelen no ser muy relevantes, pues cuando llegan a ocurrir se ha desarrollado ya un fuerte mercado negro de divisas, en el que se realiza una parte significativa de la transacciones económicas internacionales. Bolivia en 1985 es un buen ejemplo de ello.

41. Ramos (1986) ha señalado que una forma de hacer frente a este problema está en la secuencia de las políticas: éstas no deberian implementarse simultáneamente, sino que primero debería realizarse el ajuste en el tipo de cambio y sólo una vez hecho ésto aplicar políticas de reducción de la demanda agregada. El FMI habrla seguido muchas veces esta secuencias, pero al parecer por razones muy diferentes: la dificultades existentes para incorporar el tipo de cambio en su modelo de PF (Véase Buira 1983).

42. L. Taylor (1989, p. 19) sostiene que "el eslabonamiento entre el dinero y la inflación resulta ser un poco más efectivo si a los precios no les son fijados topes $u$ otro tipo de reglas administrativas, y si los componentes del costo, tales como el salario y el tipo de cambio, no están indizados a la tasa corriente de inflación". Para Taylor "la inflación se aproxima más al modelo monetarista cuando la mayor parte de los mercados de la economía responden al mecanismo de precios (los ejemplos más usuales son los pro- 
De ahi que con la contracción del crédito de los programas se controle sólo una parte de las fuentes inflacionarias (si acaso esa parte es importante en el pais en cuestión) y la inflación pueda seguir siendo alimentada por otros canales. Ramos (1986) ha hecho hincapié en la importancia de la distinción entre los distintos componentes de la inflación. No sólo debe distinguirse entre la inflación por demanda, la inflación por costos y la inflación estructural, sino también entre estos tres tipos de inflación y la inflación inercial, que está vinculada estrechamente a las expectativas y a determinados arreglos institucionales (Ramos 1986). ${ }^{43} \mathrm{EI}$ Fondo, sin embargo, no suele ver más allá de la inflación por demanda. Un factor que ha sido siempre ignorado es el papel que pueda jugar la estructura de mercado en la dinámica de los precios.

La inflación inercial en particular puede ser muy importante en los casos de inflaciones persistentes (Ramos 1986). En efecto, en aquellos paises en que la inflación se ha hecho ya un fenómeno permanente es decir, en una buena proporción de los paises subdesarrollados, o de candidatos al ajuste - las expectativas y arreglos institucionales especiales (como la indización) suelen jugar también un rol importante en la dinámica de los precios, y pueden llegar incluso a constituir el componente más importante de la inflación, que en este caso se vuelve básicamente inercial. Esto explicaria en buena medida por qué existen casos en que aún cuando se tenga un control adecuado sobre los agregados monetarios, una inflación mundial baja, un crecimiento (que puede ser cero) de los salarios acorde con la productividad, un tipo de cambio estable y descontado posibles efectos estacionales, la inflación siga estando muy por encima de la inflación mundial. Para no ir muy lejos, el caso de El Salvador en el último año pudiera ilustrar esta aparentemente paradójica situación.

Para ser justos con el Fondo, hay que decir que muchas veces sus programas se preocupan (injustamente) también por un factor inflacionario via costos: el aumento de los salarios nominales. Este, sin embargo, es un factor sobre el cual las autoridades económicas tienden a tener un menor control (el caso de los salarios mínimos pudiera ser diferente), sobre todo en el marco de una inflación persistente. En princi-

ductos alimenticios y los servicios) y la indización de los pagos nominales no está extendida. La política de precios tope o de precios administrados, sumada a la indización, apoyan más las inflaciones que se observan dentro de la linea estructuralista" (/bid., p. 36).

43. Ramos (1986, p. 25) sostiene que los enfoques de demanda, de costos y estructuralista de la inflación explican solamente "las causas del brote inflacionarios (que puede o no existir), pero no su persistencia". 
pio, éstas deberian ser capaces de controlar por lo menos los salarios en el sector público, pero ésto no siempre es posible. La férrea oposición de los sindicatos al deterioro de los salarios reales de sus agremiados es un factor importante que lo imposibilita. En lo que se refiere a los salarios en el sector privado, el problema está básicamente fuera del control de las autoridades: es una variable fundamentalmente exógena, cuyo evolución en ese marco depende de la correlación de fuerzas entre trabajadores y empresarios.

Estos factores no impiden, sin embargo, que generalmente los salarios reales caigan en el marco de los programas de estabilización. No obstante, este resultado está más asociado a que el ajuste (en los salarios nominales) por la inflación suele ser sólo parcial, que a que los salarios nominales permanezcan constantes. De esta manera, al margen de la voluntad del Fondo, en la práctica difícilmente puede ejercerse un control total sobre este otro factor inflacionario. El control se vuelve aún más difícil una vez se han desarrollado esquemas institucionales, como la indización, con el fin de protegerse contra los efectos redistributivos de la inflación.

Por último, con relación al producto, la cuestión no parece tan inexplicable. Primero, no es una preocupación importante de los programas del Fondo aumentar o mantener el nivel de actividad económica. Más bien, el ajuste externo suele requerir todo lo contrario. Segundo, en tanto que las medidas que se adoptan se concentran, casi siempre, exclusivamente en la contracción directa de la demanda o tienden a contraerla indirectamente en el corto plazo (como la devaluación), no pueden sino resultar en una contracción de la producción. Tercero, en los paises subdesarrollados algunas de las medidas típicas de los programas del Fondo tienen un afecto adverso sobre la produción a través de la oferta (van Wijnbergen 1986). Vínculado a ésto estaria, por último, el hecho de que en los paises subdesarrollados la devaluación tiende a ser contractiva en el corto plazo.

En este contexto, con frecuencia el problema que se plantea el Fondo no es como maximizar el crecimiento sujeto a la estabilización, sino más bien -si es que en realidad existe la preocupación por el producto (Edwards 1990 sugiere que no) - como minimizar la caida del producto dadas las metas de estabilzación. Una mayor selectividad en el ajuste externo y una disponibilidad adecuada de recursos podrian, no obstante, constituir elementos útiles para al menos suavizar el impacto recesivo de los programas. 


\section{Observaciones finales}

Tanto para los paises subdesarrollados en general, como para El Salvador en particular, hemos podido constatar que los programas de ajuste del FMI tienen una serie de problemas. Nuestra hipótesis es que tales problemas están relacionados con un diagnóstico inadecuado de los desequilibrios macroeconómicos, y con del carácter rígido y poco refinado del marco analítico que sirve de base a la implementación práctica de los programas. Estos defectos se traducen en un diseno, consistencia e implementación deficientes de los programas, lo cual se refleja en una eficacia bastante pobre de los mismos y en importantes costos económicos y sociales (producción, empleo, distribución del ingreso y pobreza).

Ahora bien, independientemente de su eficacia estabilizadora, ¿tienen los programas que ser necesariamente recesivos y con costos en términos de distribución del ingreso?. Aún limitándonos al pobre diagnóstico del Fondo, hay razones, tanto teóricas o analíticas como empiricas, para pensar que no. En el caso de la inflación, por ejemplo, si tal como sostiene el Fondo ésta responde a un crecimiento excesivo de la demanda nominal, en principio su abatimiento no tiene por qué ocasionar inevitablemente cambios en las variables reales, como empleo, producción y distribución (Ramos 1986). Aunque en la práctica ha resultado bastante dificil reducir la inflación sin deteriorar esas variables reales - se trate o no de una estabilización fondomonetarista- también existen razones para pensar que las deficiencias de los programas del Fondo no hacen sino incrementar esa dificultad.

Se necesita, por lo tanto, desarrollar enfoques alternativos de estabilización, que, sin ser más ineficaces, eliminen o al menos minimicen los costos de los actuales, y que sean viables más allá del corto plazo. Los enfoques heterodoxos más o menos serios que hasta ahora han sido propuestos están todavia lejos de ser una alternativa superior al enfoque del Fondo, a pesar de partir de un diagnóstico más adecuado; las experiencias de países como Argentina y Brasil con sus programas de 1985 y 1986, respectivamente, estarian indicando ésto. ${ }^{44}$ Por su puesto, la alternativa tampoco se encuentra en el (poco serio) enfoque populista basado en cruzarse de brazos o hacer totalmente lo opuesto a los programas fondomonetaristas. Esta alternativa ha mostrado no tener costos de corto plazo, pero si costos de mediano plazo que no tienen

44. Véase Sánchez (1987) y Hilker (1987). 
absolutamente nada que envidiar a los de los programas del Fondo.45 Excluyendo este último enfoque, pareciera que, por hoy, la magnitud de los costos de la estabilización estaría más en función de la disponibilidad de recursos (aunque esta es un arma de doble filo) para hacer frento al ajuste y de las características estructurales de las economias, que de diferencias sustanciales en los enfoques estabilizadores. Naturalmente, esto no significa que no puede haber alternativas o que los enfoques existentes no puedan ser mejorados.

No corresponde juzgar aqui las deficiencias de los enfoques estabilizadores distintos a los del Fondo, pero en cuanto al de éste está bastante claro que su diagnóstico, diseshoo e implementación necesitan ser mejorado sustancialmente. Los programas deberian, asimismo, ser más flexibles y adaptarse a las caracteristicas concretas de cada país. Como ha sefhalado Buira (1983, p. 128), "pese a las afirmaciones oficiales [del Fondo], el hecho fundamental sigue siendo que llaman mucho más la atención las semejanzas entre los programas que sus diferencias". Esto se aplica tanto a programas en paises distintos, como a programas en circunstancias distintas en un mismo pais. El enfoque de recorte del crédito interno, cualquiera que sea el origen de los desequilibrios, no sólo suele resultar ineficaz muchas veces, sino también innecesariamente costoso cuando los desequilibrios no tienen su origen en una sobreexpansión de la demanda.

Continuar por más tiempo con un enfoque que ha permanecido básicamente inalterado por más de tres décadas, pese a todos los cambios tanto en la estructura de la economias domésticas como en el contexto económico internacional y en la misma teoria económica que ha inspirado al Fondo, no contribuirá sino a que los programs sigan teniendo problemas no sólo de viabilidad, aceptabilidad social y política y costos, sino también de eficacia para corregir los desequilibrios macroeconómicos.

45. De manera independiente a esos enfoque heterodoxos, dentro del paradigma neoclásico, McKinnon (1973) sugirió un enfoque de estabilización alternativo que descansaria en la expansión de la oferta y no sería, por tanto, recesivo. El enfoque de McKinnon, que él denomina de "estabilización afortunada", se basaria en la eliminación de la represión financiera y en particular en la elevación de las tasa reales de interés. Hay que señalar, sin embargo, que algunos países del Cono Sur experimentaron en los sententa con este enfoque, y su experiencia no resultó muy "afortunada" (Véase Zahler 1986, 1987). Dentro del "paradigma estructuralista", Lance Taylor (1989) ha ofrecido algunas sugerencias para mejorar el programa de estabilización del Fondo. 
Aunque concebidos en parte para responder al sesgo recesivo de los porgramas de estabilización del Fondo, los programas de ajuste estructural que promueve el Banco Mundial dificilmente pueden ser una alternativa, porque también tienen costos similares de corto plazo (y quizá también de mediano y largo plazo en términos de distribución del ingreso). Asi, estos últimos pueden muy bien reforzar el efecto recesivo de la estabilización. El efecto de largo plazo de los programas de ajuste estructural, teóricamente postivo, es más difícil de juzgar, y no corresponde considerarlo acá; pero, como alternativa o suplemento a los programas de estabilización, el efecto relevante en este caso sería el de corto plazo. $Y$ en el corto plazo al menos, el ajuste estructural también tiene costos. Además, en el corto plazo, el ajuste estructural no sólo contribuye muy poco a solventar los desequilibrios macroeconómicos que buscan afrontar los programas del Fondo, sino que suele tender incluso a agravarlos. Tal es el caso, por ejemplo, de la liberalización de precios, en cuanto a la inflación; y de las liberalizaciones del comercio exterior no acompañadas por una devaluación compensada, en cuanto a la balanza de pagos. Por esta vía también tenderian a incrementarse los costos de corto plazo.

Ahora bien, mientras no se desarrollen enfoques estabilizadores alternativos que, sin ser más ineficaces, reduzcan los costos de los actuales, deberia de tratarse al menos de minimizar los efectos redistributivos y pauperizadores de los programas mediante la adopción de políticas compensatorias. ${ }^{46}$

Por otra parte, es necesario una actitud más realista y más modesta (y honesta) de parte del Fondo. Muchas de las relaciones entre variables macroeconómicas claves que el Fondo establece con toda certeza ni siquiera han sido dilucidadas aún por la teoría económica. Tal es el caso de la relación entre devaluación y nivel de actividad económica, por ejemplo. Buira (1983) ha señalado que puesto que hay razones teóricas tanto a favor como en contra de que la devaluación afecta positivamente a la actividad económica, a lo sumo podría decirse que la relación es indeterminada, por lo menos en el corto plazo. Pero inclusive ésto podría ser mucho para algunos paises, pues hay evidencia empirica de que en los países subdesarrollados en el corto plazo esta relación suele ser todo lo contrario a lo que sugiere el Fondo. Muchas veces, el

46. Esto es algo que el Banco Mundial ha hecho para sus programas de ajuste estructural. En los últimos tres años, el Fondo también habría emepezado a preocuparse por los costos sociales del ajuste y en algunos de sus programas se habrian adoptado políticas compensatorias. Véase Finanzas y Desarrollo, Noviembre 1990. 
optimismo del Fondo, derivado de un mal diagnóstico, de una falta de realismo o de su afán por hacer más aceptables sus programas, no hace sino socavar la credibilidad de éstos. Esto suele tener consecuencias graves, particularmente en casos de inflaciones altas y con un importante componente inercial, en que la credibilidad es importante en el éxito de los programas.

Cabe sefalar también las dificultades analíticas para definir adecuadamente las metas de balanza de pagos de los programas de estabilización. A este respecto, nuevamente Buira (1983) ha llamado la atención sobre lo difuso del concepto de sustentabilidad de una posición externa: "es evidente que el concepto de una posición de balanza de pagos sostenible implica la estimación de variables económicas que no pueden ser objeto de cuatificación precisa $y$, por to tanto requiere un juicio sustancial de valor" (p. 138). Esto pudiera tener implicaciones de cara al crecimiento económico, en la medida en que en los paises subdesarrollados el financiamiento externo suele desempenar un papel importante en esa esfera. ${ }^{47}$ En cualquier caso, el punto es que, tal como la teoria ha establecido hasta ahora, la sustentabilidad de la cuenta corriente es un concepto bastante relativo, que no puede reducirse a los rígidos criterios de los programas del Fondo, sobre todo en aquellos paises que están aún muy lejos de resolver siquiera la problemática de su crecimiento, como es el caso de la inmensa mayoría de paises del Tercer Mundo.

Estas consideraciones nos conducen a otro factor de naturaleza estructural en el ajuste externo y sus costos macroeconómicos. Este ha sido planteado, entre otros, por Arellano (1986). Arellano sefiala que hay básicamente tres formas de lograr el ajuste externo: i) aumentando la producción de bienes transables; ii) disminuyendo el gasto en bienes transables; iii) disminuyendo la demanda y, por tanto, la producción de bienes no transables. Las dos últimas modalidades son las que acarrean costos macroeconómicos (contracción producción y empleo). Las condiciones estructurales de la economia serian muy importante en cuanto a la modalidad que el ajuste pueda asumir, en particular el peso del sector productor de bienes transables en el producto y la vocación exportadora del aparato productivo. Esto depende mucho de las políticas seguidas en el pasado y del tipo de bienes que se exporta. Los bienes manufactu-

47. Este es un viejo y debatido punto de la economía del desarrollo, que, por cierto, gozó de mucho respeto en la década de los sesenta al ser formalizado en el modelo de las dos brechas. El estudio comparativo sobre crecimiento económico de Chenery et. al. (1986) lo ha puesto de relieve nuevamente. 
rados, por ejemplo, son más suceptibles de responder a variaciones en los precios relativos en un periodo más corto de tiempo (Arrellano 1986).

Asimismo, cuanto más grande sea en términos relativos el sector productor de transables, mayor flexibilidad habrá y es más factible realizar el ajuste mediante la expansión de la producción de los comerciabales. En este caso el ajuste pudiera caer más sobre la producción exportable (aumento de las exportaciones) (Arellano 1986). ${ }^{40}$ Naturalmente, esto último supone que se tiene una vocación exportadora -que no puede desarrollarse en el periodo del ajuste mismo. Si esta vocación no existe, como es el caso de los paises con orientación hacia adentro, este tipo de ajuste es más dificil y por tanto el ajuste en general se vuelve más costoso. En este caso, si el mercado interno está ya saturado, la combinación restricción de la demanda y una devaluación puede muy bien generar una contracción de esas industrias.

Por último, el modelo del Fondo no es sólo bastante burdo, sino también sumamente global o agregado. Arellano (1986) y Martán (1986) han planteado la idea de la aplicación de algún criterio de selectividad en la estabilización, a fin de hacer frente al menos a las deficiencias derivadas del carácter global o agregado del modelo, sin necesariamente afectar el objetivo global buscado. A este respecto, se ha sefialado, por ejemplo, las diferencias en términos de costos entre reducir el gasto corriente y el gasto de capital, o entre reducir de manera uniforme la demanda y reducir preferiblemente la de importados (Arellano 1986). Tampoco sería igual, en términos de costos, reducir el déficit externo devaluando totalmente que devaluando parcialmente mediante instrumentos de política de comercial que afecten la importaciones de bienes "no esenciales", aunque en principio pueden lograrse resultados de balanza de pagos similares por cualquiera de las dos vias.

También, como hemos visto arriba, se han sefialado diferencias entre realizar el ajuste externo reduciendo la demanda y produción de no transables y aumentando la produción de comerciables o reduciendo el gasto en ellos (Arellano 1986). Esto es particularmente importante cuando hay desempleo - caso usual - y un incremento produccón de transables no requiere necesariamente una reducción de la de no transables, que -como la construcción, por ejemplo- suelen ser intensivos en trabajo.

48. Según Arellano (1986, p. 90), más que la implementación de una modalidad diferente de políticas con relación a América Latina, el ajuste expansivo de Corea a principios de los ochenta estuvo asociado a la importancia y características del sector de bienes transables y de las exportaciones en su economia. 
Podria objetarse a la selectividad aduciendo efectos desfavorables en la asginación de recursos (en la eficiencia). Esta pudiera ser una crítica válida; pero igual puede ocurrir con políticas no discriminatorias, como la devaluación o la contracción del crédito doméstico. La primera promovería indiscriminadamente las exportaciones y la sustitución de importaciones, sean estas o no eficientes. Teniendo en cuenta las dificultades en el modelo del Fondo para definir operativamente la sobrevaluación cambiaria, eso seria bastante probable. La segunda, sobre todo cuando el acceso al mercado financiero está muy segmentado, desestimularía también a la producción en general (transable y no transables) en el corto plazo, sea o no eficiente. Tanto en el caso de tratamiento uniforme como en el de tratamiento selectivo, se pueden cometer errores al estar favoreciendo activadades no eficientes o desfavoreciendo actividades eficientes; solo que en el primero el costo de corto plazo del ajuste sería mayor. Un problema similar ocurre con los efectos de las distintas medidas en la distribución del ingreso: los esquemas selectivos serian más aptos para minimizar este tipo de costos, sin necesariamente amenazar la consecusión de los objetivos globales de estabilzación.

Toda vez que las distorsiones provocadas por este tipo de selectividad sean eliminadas una vez la posición externa ha mejorado lo suficiente (y teniendo en cuenta que la modalidad no discrimatoria pudiera tener similares problemas), el problema principal con esta modalidad no estaria en sus efectos sobre la eficiencia, sino más bien en que su eficacia estabilizadora depende en buena medida de factores institucionales que vuelven administrativamente difícil su buen manejo, asi como de las caracteristicas estructurales de la economia, algo muy difícil de alterar en el corto plazo.

\section{REFERENCIAS BIBLIOGRAFICAS}

L. Ahamed (1986). "Stabilization Policies in Developing Countries". The World Bank Research Observer, vol. 1, \# 1, pp. 79-110.

J.P. Arellano (1986). "Los costos de equlibrar la balanza de pagos en América Latina", en R. Cortázar (ed.), Politica macroeconómica. Una perspectiva latinoamericana. Santiago: CIEPLAN. pp. 63-94.

Banco Central de Reserva de El Salvador (1987). Memoria de Labores 1987.

--.-- Revista Mensual, varios años.

Banco Mundial (1988). Structural Adjusment Lending. An Evaluation of Ten Years of Experience. Washington: The World Bank.

W. Beveridge y M. Kelly (1980). "Fiscal Content of Financial Programs. Supported by Stand-By Arrangements in the Upper Credit Tranches, 1969 . 1978". IMF Staft Papers vol 27, pp. 151-174. 
A. Buira (1983). "La programación financiera y la condicionalidad del FMI". EI Trimestre Económico \# 197.

M. Corden (1986). Inflation, Exchange Rates and the World Economy. Chicago: The Univeristy of Chicago Press.

A.D. Crockett (1981). "Stabilization Policies in Developing Countries: Some Policy Considerations". IMF Staff Papers 28, \# 1, pp. 54-89.

H. Chenery, S. Robinson y M. Syrquin (1986). Industrialization and Growth: A Comparative Study. Washington: The World Bank.

S. Edwards (1988). Exhange Rate Misalignment in Developing Countries. Washington: The World Bank.

--- (1990). "El FMI y los paises en desarrollo: una evaluación crítica". El Trimestre Económico \# 227, pp. 611-663.

Fondo Monetario Internacional (1985 y 1990). El Salvador: Recent Economic Developments. Mimeo.

S. Fischer (1986). "Issues in Medium-Term Macroeconomic Adjustment". The World Bank Research Obsenver, vol. 1, \# 2, pp. 163-182.

Carolina de Franco (1990). "La experiencia de un mercado paralelo en El Salvador". Realidad Económico-Social \# 17, pp. 473-531.

J. Frenkel (1980). "A Synthesis of the Monetary and Keynesian Approach to Balance of Payments Theory". Economic Journal, vol. 90 (Septiembre), 58292.

FUSADES (1989). Caracterización socio-económica de la población de El Salvador. San Salvador: FUSADES.

R.L. Ground (1984). "Los programas ortodoxos de ajuste en América Latina". Revista de la CEPAL \# 23, pp. 47-84.

M. Goldstein y S. Montiel (1986). "Evaluating Fund Stabilization Programs with Multicountry Data: Some Methodological Pitfalls". IMF Staff Papers, vol. 33, pp. 304-44.

H. Hilker (1987). "Desarrollos inflacionarios en el Plan Cruzado y en el Plan Austral desde una perspectiva teórica y empírica". Economia de América Latina \# 16, pp. 153-62.

H. Johnson (1961)."Towards a General Theory of the Balance of Payments", en H.G. Johnson, International Trade and Economic Growth: Studies in Pure Theory. Cambridge: Harvard University Press.

O. Johnson y J. Salop (1980). "Distributional Aspects of Stablization Programs in Developing Countries". IMF Staff Papers, vol 27, \# 1, pp. 1-23.

M. Kelly (1982). "Fiscal Adjustment and Fund-Supported Programs 1971-1980". IMF Staff Papers vol. 29, pp. 561-602.

P. Kenen (1985). "Macroeconomic Theory and Policy: How the Closed Economy 
Was Opened", en R. Jones y P. Kenen (eds.), Handbook of International Economics, vol. 2. N. York: Elsvier, pp. 625-77.

M. Khan y M. Knight (1981). "Stabilizations Programs in Developing Countries: A Formal Framework". IMF Staff Papers, vol. 28, \# 1, pp. 1-53.

P. Krugman y L. Taylor (1978). "Contractionary Effects of Devaluation". Journal of International Economics, vol. 8, pp. 445-56.

M. Martán (1986). "La política fiscal macroeconómica", en R. Cortázar, op. cit., pp. 97-152.

R. McKinnon (1973). Dinero y capital en el desarrollo económico. México: CEMLA.

-.- (1981). "The Exchange Rate and Macroeconomic Policy: Changing Postwar Perceptions". Journal of Economic Literature, vol. 19, \#2 (Junio), pp. 531557.

P. Meller (1987). "Revisión de los enfoques teóricos sobre el ajuste externo y su relevancia para América Latina". Revista de la CEPAL \#34.

Ministerio de Planificación (1990). Evolución económica y social. Tercer informe trimestral 1990. San Salvador: MIPLAN.

J.J. Polak (1957). "Monetary Analysis of Income Formation and Payments Problems". IMF Staff Papers, pp. 1-50. También en El Timestre Económico \# 96.

R.C. Porter y S.I. Ranney (1982). "An Ecclectic Model of Recent LDC Macroeconomic Policy and Analysis". World Development, 751-765.

J. Ramos (1986). "Pollticas de estabilización", en R. Cortázar, ed., op. cit., pp. 19-59.

T. Reichman y R. Stillson (1978). "Experience with Balance of Payments Adjusment". IMF Staff Papers, vol. 25, pp. 278-292.

Roberto Rivera (1988). "La inflación en El Salvador". Realidad Económico-Social \# 1, pp. 7-56.

E.W. Robichek (1985). "Financial Programming as Praticed by the IMF". Banco Mundial: manuscrito inédito.

Nolvia Saca y Roberto Rivera (1987). "Políticas de estabilización y deuda externa en El Salvador". Boletín de Ciencias Económicas y Sociales, año 10, \# 5.

J. Salop y E. Spitäller (1980). "Why Does the Current Account Matter". IMF Staff Papers, vol. 27, \# 1, pp. 101-134.

L. Taylor (1989). "Variedades de la experiencia estabilizadora". Investigación Económica \# 189, pp. 11-52.

H. Sánchez (1987). "Nuevos enfoques de política económica en América Latina". Economia de América Latina \# 16, pp. 69-96. 
Alexander Segovia (1991). "Los desequilibrios macroeconómicos en El Salvador". Politica Económica, vol. I, \# 6 (Abril-Mayo).

S. van Wijnbergen (1986). "Exchange Rate Management and Stabilization Policies in Developing Countries". Journal of Development Economics.

R. Zahler (1986). "Política monetaria y financiera", en R. Cortázar, op. cit.

... (1987). "Estrategias financieras latinoamericanas: la experiencia del Cono Sur". Mimeo. 